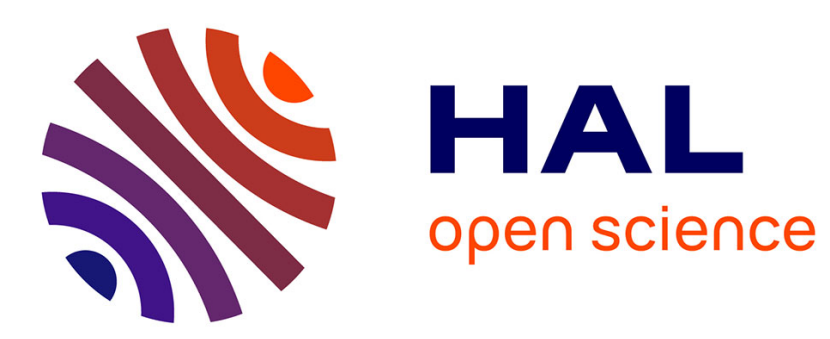

\title{
What is the epipleurite? A contribution to the subcoxal theory as applied to the insect abdomen
}

\author{
Thierry Deuve
}

\section{To cite this version:}

Thierry Deuve. What is the epipleurite? A contribution to the subcoxal theory as applied to the insect abdomen. Annales de la Société Entomologique de France, 2018, 54 (1), pp.1-26. 10.1080/00379271.2018.1431568 . hal-01744623

\section{HAL Id: hal-01744623 \\ https://hal.sorbonne-universite.fr/hal-01744623}

Submitted on 27 Mar 2018

HAL is a multi-disciplinary open access archive for the deposit and dissemination of scientific research documents, whether they are published or not. The documents may come from teaching and research institutions in France or abroad, or from public or private research centers.
L'archive ouverte pluridisciplinaire $\mathbf{H A L}$, est destinée au dépôt et à la diffusion de documents scientifiques de niveau recherche, publiés ou non, émanant des établissements d'enseignement et de recherche français ou étrangers, des laboratoires publics ou privés. 
Deuve T. 2018 - What is the epipleurite? A contribution to the subcoxal theory as applied to the insect abdomen. Annales de la Société entomologique de France (N. S.), $54: 1-26$. doi: 10.1080/00379271.2018.1431568.

\title{
What is the epipleurite? A contribution to the subcoxal theory as applied to the insect abdomen
}

\author{
Thierry Deuve
}

Muséum National d'Histoire Naturelle, ISYEB, UMR7205, MNHN, CNRS, EPHE, UPMC, ParisSorbonne, CP50, Entomologie, 57 rue Cuvier, F-75005 Paris, France <deuve@ mnhn.fr>

\begin{abstract}
The epipleurites were originally described by Hopkins in 1909 on the imago and larva of a beetle. Then this term was widely used in insect morphology, mainly for larvae, to designate certain sclerites of the pleural region. They have recently been interpreted as tergopleural (i.e. pleural but not strictly appendicular) by Deuve in 2001, but a study of embryonic development by Kobayashi et al. in 2013 has shown that they are instead eupleural (i.e. appendicular) and correspond to a dorsal part of the subcoxa. Their presence in the abdominal segments of insects illustrates the fundamental importance of the subcoxa in segmental structure, with a function of anchoring and supporting the appendage when the latter is present. However, the epipleurites are normally separated and functionally dissociated from the coxosternum, which integrates the ventral component of the subcoxa. In females, the epipleurite of segment IX of the abdomen corresponds to the gonangulum, as already pointed out by Deuve in 1994 and 2001, and it is involved in gonopod articulation. At segments VIII and IX of both males and females of holometabolans, the formation process of the genital ducts leads to an internalisation of the whole subcoxosternum (i.e. the coxosternum with the exception of the coxal and telopodal territories), and it is the two flanking epipleurites that ventrally close the abdomen in relation to the rearward displacement of the gonopore. This model may be generalised, in its broad lines, to a large part of the hemimetabolans. The body plan of the insect abdomen underlines the morphological and functional importance of the subcoxa in its fundamental structure, but the study of the Hexapoda in general also indicates the presence of a more proximal segment, the precoxa, which would belong to the groundplan but is more cryptic because it is often closely associated with the subcoxa and/or the paranotal lobe. Its location, which is sometimes on the ventral flank of the paranotal lobe, is in line with the hypothesis of a dual origin of the pterygote wing.
\end{abstract}

Résumé. Qu'est-ce qu'un épipleurite ? Une contribution à la théorie subcoxale appliquée à l'abdomen des Insectes. Les épipleurites ont été d'abord décrits par Hopkins en 1909 sur l'imago et la larve d'un Coléoptère. Puis ce terme a été largement utilisé en morphologie de l'Insecte pour désigner des sclérites de la région pleurale, surtout pour les larves. Ils ont récemment été interprétés comme tergopleuraux (c'est-à-dire pleuraux mais non strictement appendiculaires) par Deuve en 2001, mais une étude du développement embryonnaire par Kobayashi et al. en 2013 a montré qu'ils étaient en réalité eupleuraux (c'est-à-dire appendiculaires) et correspondaient à la partie dorsale de la subcoxa. Leur présence aux segments abdominaux des Insectes illustre l'importance fondamentale de la subcoxa dans l'architecture segmentaire, avec une fonction d'ancrage et de support de l'appendice lorsque celui-ci est présent. Cependant, les épipleurites sont habituellement séparés et fonctionnellement dissociés du coxosternum, lequel intègre la composante ventrale de la subcoxa. Chez les femelles, l'épipleurite du segment IX de l'abdomen correspond au gonangulum, comme déjà indiqué par Deuve en 1994 et 2001, et participe à l'articulation du gonopode. Aux segments VIII et IX des mâles et des femelles d'Insectes Holométaboles, la morphogenèse des conduits génitaux provoque une internalisation de tout le subcoxosternum (c'est-à-dire le coxosternum moins les territoires coxaux 
et télopodiaux), et ce sont les deux épipleurites adjacents qui ferment ventralement l'abdomen en accompagnement du déplacement vers l'arrière du gonopore. Ce modèle peut être étendu, dans ses grandes lignes, à une large partie des Insectes hémimétaboles. Le plan structural de l'abdomen des Insectes souligne l'importance morphologique et fonctionnelle de la subcoxa dans l'architecture fondamentale, mais l'étude de tous les Hexapodes indique aussi la présence d'un article plus proximal de l'appendice, la precoxa, qui appartiendrait au plan de base mais serait plus discret car souvent étroitement associé à la subcoxa et/ou au lobe paranotal. Sa position, souvent au flanc ventral du lobe paranotal, s'accorde avec l'hypothèse d'une origine duale de l'aile des Ptérygotes.

Keywords. Arthropoda, Hexapoda, Insecta, morphology, morphogenesis, segment, limb, pleurite, sternite, subcoxa, precoxa, ectodermal genitalia, wings.

\section{Introduction}

For more than a century, the question of structure of the arthropod segment along its dorsoventral axis has been subject of intensive debate. In theory, this structure corresponds to a simple model: a dorsal tergum is separated from a ventral sternum by lateral pleura (Audouin 1824; MilneEdwards 1851). In practice, however, it is often difficult to delimit these respective territories if we consider the morphological diversity of arthropods and the adaptive differentiations that respond to mechanical and functional constraints. Sclerified areas and membranous areas delineate visible territories that do not always correspond to the fundamental morphological fields. Sclerites of different origins may merge, or, conversely, a given sclerite may be reduced or fragmented and partially replaced by a membranous area with blurred or indefinable limits. Invaginations of some skeletal territories to form internal ducts or apophyses for muscle attachment have also been reported. Several approaches make it possible to search for the identity and limits of the original territories: the classical methods of comparative anatomy, including study of muscles, whose inserts can act as landmarks, those of descriptive and comparative embryology, and the more recent ones of developmental genetics using molecular markers of anatomical territories. Over the past few decades, the combined use of these methods has illustrated the complexity of the issues involved, but has also clarified our understanding of the fundamental organisation of the skeleton.

Pleural regions present the majority of problems, because their boundaries are ipso facto those of the tergal and sternal regions. In addition, they include the limbs and a subsequent question is whether the pleura are entirely appendicular in nature or whether some parts of the pleura would instead be 'non-appendicular' or 'formerly appendicular'. Hypothetical homologies with a prearthropodan ancestor may even be sought. Added to this is the complex structure of the arthropodal limb itself, of a pleural nature, whose fundamental organisation needs to be elucidated in order to uncover the true pattern of its diversification within the different arthropod lineages and, for a given organism, according to the metamere considered.

The pleura are lateral areas, but the insertion of the arthropodal limb has shifted to a more lateroventral location. This arrangement and functional necessities lead to a differentiation of the most proximal segments of the appendage (precoxa and coxa in crustaceans, precoxa and subcoxa in hexapods): on the ventral side, these segments tend to merge with the sternum or even to replace it (Börner 1921; Weber 1928; Ferris 1939, 1940a), on the dorsal side, they tend to be embedded into the body wall, or even to merge with it (Börner, 1921). In the dorsal region of the pleuron, there is indeed a peculiar area situated between the apparent base of the appendage and the tergum, the interpretation of which is problematic. Respiratory organs - the spiracles in Hexapoda and Myriapoda - are located in this laterodorsal region. Crampton (1914) proposed the name eupleurites for the pleural sclerites belonging to the limb, and Prell (1913) introduced the term tergopleurites for those which, being 'not appendicular', are located between the base of the limb and the genuine tergum (the paranotal lobes 
could probably be included among these). In the Hexapoda, Snodgrass first named some laterodorsal sclerites "tergopleurites" (1927), then "paratergites" (1931) and finally "laterotergites" (1935a), because, from his final point of view, they belonged not to the limb but to the tergum. He then drew a boundary, called the "dorsopleural line" $(1931,1935 \mathrm{a}, 1958)$, which would separate the pleural and tergal regions. This "pleural line" was the so-called "pleural suture" of Hopkins (1909) with respect to the abdomen. It should be noted that in Snodgrass' diagrams (ibid.), the spiracles are more dorsal than this boundary and therefore located in the tergal or, more precisely, 'laterotergal' area. This led me to rename the "laterotergites" of Snhodgrass (1935a) "epipleurites", using the terminology of Hopkins (1909) created for both imago and larva of Coleoptera, because they seemed to me to be pleural rather than tergal in nature (Deuve 1994, 2001a). In my view, and following Hopkins (1909), they were tergopleurites in the sense of Prell (1913). It can also be noted that Snodgrass (1935a, 1958) later identified as "epipleurites" or "epipleural sclerites" the subalar and basalar sclerites of the pterygote thorax, lying between the limb-base and the notum.

In a recent work on the embryonic development of a carabid beetle, Kobayashi et al. (2013) correctly note that I misplaced the dorsopleural or longipleural fold separating the epipleurite from the subcoxa (Deuve 1988, 1994, 2001a), confusing it in the thorax of a Carabus larva with the paracoxal furrow separating the catepimerite and the anepimerite. Consequently, anepimerite and epipleurite were confused in the metathoracic segment, the latter losing its subcoxal identity. However, I had only reproduced the successive diagrams of Snodgrass that drew the "dorsopleural line" on larvae of Silphidae (Snodgrass 1931, "Fig. 3B") and Carabidae (Snodgrass 1927, "Fig. 25"; 1935a, "Fig. 139B"; 1958, "Fig. 8G"). Indeed, Snodgrass (1935a) interpreted this larval thoracic anepimerite as a laterotergite or, later (1958), as a pleurite more dorsal than the anapleurite. It must be noted in this respect that Snodgrass himself reproduced an error of Hopkins (1909, "Fig. 3"), who, on an imago of Coleoptera, confused under the unique name "pleural suture" the true thoracic pleural furrow and the abdominal dorsopleural furrow. Snodgrass (1931, p. 11) subsequently corrected this error of homonomy for the imago, but he did not correct it for the larva as can be seen from his figures cited above. This misinterpretation of larval thoracic segments led to a consecutive error in abdominal segments by serial comparison. The understanding of this repeated error now makes it possible to correct the general interpretation of the abdominal epipleurites (abdominal laterotergites sensu Snodgrass 1935a) by giving them an identity more coherent with the hexapodan segment model according to the general subcoxal theory.

In his fundamental work on the skeletal morphology of a scolytid beetle, Hopkins (1909) placed great importance on the longitudinal fold which, in the abdominal pleural region, separates a dorsal epipleurite and a ventral hypopleurite. As mentioned above, Snodgrass (1927, 1931, 1935a) named this fold the "dorsopleural line" and for this reason considered the sclerites located above this line as tergal and those below it as pleural (subcoxal). Thus the "epipleurites" of Hopkins (1909) and Böving \& Craighead (1931) became "paratergites" or "laterotergites". Returning to the conception of Hopkins, I adopted the term epipleurite and named the dorsopleural line of Snodgrass the "longipleural furrow" (Deuve 1994). It should be noted, however, that the epipleurite of Hopkins described for the imago of Dendroctonus (Scolytidae) is located around the spiracle and not below it, as in the campodeiform larva of Carabus (Carabidae) that served as my model. The two territories are not exactly homologous and Böving (1914) made a useful distinction between the abdominal "pleural suture" in the sense of Hopkins and an "antipleural suture" located above it. This antipleural furrow was named "tergopleural suture" by Craighead (1916), and "dorsolateral suture" by Böving \& Craighead (1931), adding to the confusion. I actually used the term epipleurite for all beetle larvae in the classical sense generalised by Böving \& Craighead (1931), as well as by Snodgrass (1931, 1935a) under the name "paratergite" or "laterotergite". The use of the term epipleurite continues today in most works on larval morphology, but not without maintaining some confusion. As will be seen below, the meaning of this term may refer, depending on the case, to subcoxal or to subcoxal + precoxal territories.

In my previous paper (Deuve 2001a), presented at a symposium on the origin of the Hexapoda held in Paris in January 1999, I hesitated whether to interpret the "epipleural field" as a precoxal 
(appendicular) or tergopleural (not appendicular) territory, finally opting for the second hypothesis, but only after expressing my doubts. In a clumsy way, I gave too much importance to this uncertain choice, including in the title, which had the effect of misleading the reader and diverting attention from the best-supported part of my demonstration, i.e. the presence of some peculiar sclerites in the groundplan of the pterygote abdominal segments and their key involvement in the functioning of the external female genitalia after subcoxosternal plate internalisation. The denomination and interpretation of these sclerites ("epipleurites, hypopleurites, tergopleurites, laterocoxites, subcoxae, precoxae") are secondary but not minor issues. The results of Kobayashi et al. (2013) show that the epipleurites have a subcoxal identity and therefore a readjustment must be made. But this does not change the broad lines of my previous study, as will be discussed below. If it is considered that there also exists a longitudinal field in the fundamental organisation of the arthropod metamere that was formerly appendicular but not strictly part of the present arthropodal appendage, and then became located between the primary tergum and the base of the limb and possibly including the paranotal lobe, Prell's (1913) terminology could be used and the term "tergopleural field" should be applied instead of the inappropriate "epipleural field".

There are also, especially in certain Chilopoda, some sclerites named "dorsal sclerites" by Bäcker et al. (2008), located above — and not belonging to - the limb, which I marginally included in my former "epipleural field" concept. They must not now be confused with the epipleurites and, as far as we know, they would be paranotal and/or tergopleural in nature. However, these sclerites deserve special attention in reference to their possible relationship with precoxal extensions (we have in mind the origin of insect wings). In addition, Bäcker et al. point out that species showing these dorsal sclerites are often burrowing forms or species of the edaphon, a milieu that requires functional adaptations of the skeleton with losses (i.e. transformations) of the projecting paranotal lobes.

\section{The subcoxal theory}

The idea that a proximal segment of the appendage, named subcoxa by Heymons (1899), would make up most, if not all, of the pleural and ventral regions, is called the "subcoxal theory". Following the embryological observations of Heymons on Heteroptera, Börner (1921) promoted and extended this idea to many arthropods, distinguishing (p. 690) between subcoxae that are free, pleural, or integrated into a subcoxosternum. He wrote very explicitly: "It is not uncommon to observe a more or less deep fusion of the subcoxa with the sternum or tergum, as is the case with many crustaceans and hexapods, whereas a fusion with the coxa seems to have occurred only rarely" (p. 656, translated from German). Snodgrass (1927) and Weber (1928) later discussed, employed and developed this theory.

In insects, the subcoxal theory could only be really applied to the thoracic segments, where the limbs are particularly developed as legs. Snodgrass described in pterygotes a pleural wall, of a subcoxal nature, split dorsoventrally by an oblique fold called pleural furrow or pleural sulcus. This fold serves for muscular attachments, reinforced in the thoracic tagma whose locomotory function is predominant. The presence of meso- and metathoracic wings further reinforces the mechanical importance of these parietal pleura. However, if the subcoxa is a proximal segment of the limb, it should surround the base of the more distal coxa and therefore, if embedded, it would also have some anterior, posterior and ventral components. Börner (1921), Weber $(1928,1952)$ and Ferris (1939, 1940a) have shown that the subcoxa is ventrally associated or integrated with the sternum in formations whose interpretation is complex and sometimes rather speculative. Recent observations of embryonic development have confirmed the preponderant role of some ventral subcoxal formations (particularly the basisternum) in the formation of the secondary sternum, which is in fact a subcoxosternum (e.g. Uchifune \& Machida 2005). In addition, developmental genetic techniques have definitively confirmed the existence of the subcoxa as a proximal segment of the appendage of the Hexapoda, not only in the thorax, but also in the cephalic segments (Coulcher et al. 2015). Certainly, this theory may be extended to more or less all segments, including those of the abdomen. 
Despite the bitter opposition of Hansen (1930), the subcoxal theory prevailed in the following decades, before Snodgrass (1952, 1958, 1963) changed his own mind, and Bekker (1960), Sharov (1966) and Manton (1972) criticised it in quite different ways. Bekker (1960) criticised Heymons' observations and Börner's old interpretations of the articulation of the limb on the pleuron, but he seems to have been unaware of the fundamental works of Snodgrass and Weber, not citing any bibliographical reference after 1913. For Sharov (1966), the pleuron of the pterygotes was essentially precoxal in nature ("pleuron" or "basal joint corresponding to the crustacean precoxopodite", p. 186187, see also the present Figure 2), the true subcoxa being reduced to the trochantin (the latter would then be a genuine segment - the subcoxa - and not a fragment of the coxa as Snodgrass claimed in his subcoxal theory). Bäcker et al. (2008) adopted the broad lines of this interpretation. In his final model, Snodgrass $(1952,1958,1963)$ considered the whole pleural region of arthropods as resulting from differential sclerotisation of the body-wall or from fragmentation of the coxa. In doing so, he totally abandoned his former subcoxal theory. Manton (1972), who gave more importance to functional aspects than to problems of identity and homology, followed Snodgrass' later conceptions and considered the pleurites of arthropods as so many adaptations to different modes of life. For the latter author, there is no subcoxa and it is vain to try to establish such homologies.

Today, however, there seems to be a consensus in favour of the subcoxal theory. It implies the existence of a segment more proximal than the coxa, named the subcoxa. Dorsally, located between the coxa and the tergum, the subcoxa is divided in pterygote insects by the pleural furrow into an anterior episternite and a posterior epimerite. The subcoxa should not be confused with the trochantin, a basal sclerite of the appendage known for long time, which according to Snodgrass, as well as Carpentier (1947), would be genuinely coxal in nature (with serious arguments, Sharov 1966, as well as Bäcker et al. 2008, did not accept this interpretation). Some collembolans, such as Tetrodontophora and Orchesiella species, are known to have two well-defined segments, more proximal than the coxa, interpreted as precoxa (or "pretrochantin") and subcoxa ("trochantin") (Hansen 1930), also sometimes referred to respectively as "subcoxa 1" and "subcoxa 2" (Denis 1949; Deharveng 1983). These two segments have also been observed as buds during the embryonic development (Bretfeld 1963). More generally, these are two arciform sclerites that can be observed in some collembolans and that Willem (1900) has considered as true "precoxal segments", i.e. true segments more proximal than the coxa. Hansen (1930) clearly described these two segments in Nicoletia, an exobasal zygentom (note that only an ancestor or a node in phylogenetical tree may be said 'basal'; a basally branched extant clade is 'exobasal'). This observation was taken up by Sharov (1966), who observed these two segments in both Nicoletia and Tricholepidon. As Barlet \& Carpentier (1962) reported, these two segments were also observed in the Diplura as supracoxal rings, while in the Protura they have also been described as "subcoxa 1" and "subcoxa 2" by Denis (1949). These supracoxal arches, named anapleurite (subcoxa 1) and catapleurite (subcoxa 2) by Barlet and Carpentier, are separated from each other by the "paracoxal fold" (Matsuda, 1970). Bäcker et al. (2008) interpreted their presence as forming part of the hexapodan groundplan and named them respectively "eupleurite" and "trochantinopleurite". We could also use Hansen's terminology ("pretrochantin" and "trochantin") or, to make matters even easier and more definitive, the terms precoxa and subcoxa. This problem of terminology may seem a secondary question, but it has crucial theoretical implications. Although Bäcker et al.'s argumentation against the terminology employed in the works of Barlet and Carpentier, as well as those of Snodgrass (1958, 1963), is relevant considering their interpretation, it should be noted that the terms anepimeron, anepisternum, catepimeron and catepisternum had been proposed long before. They were introduced by Crampton (1909) for the pterygote thorax. Later, the terms anepisternite, anepimerite, catepisternite and catepimerite were widely used by Ferris and his school — of which Matsuda was a young member - to describe the subdivisions of the so-called subcoxa of the pterygotes (e.g. Rees \& Ferris 1939; Ferris 1940b) and it is this model that was later adopted and developed by Matsuda.

The anapleurite and catapleurite were meticulously studied by Carpentier and Barlet, who clearly observed them in Collembola, Archaeognatha, Zygentoma and Diplura (Carpentier 1946, 1947; Barlet 1946, 1950; Carpentier \& Barlet 1951; Barlet \& Carpentier 1962). In addition, François (1964, 1996) described them accurately in the Protura (Figure 1). This arrangement has also been reported in 
most orders of pterygote insects by many authors. In this latter clade the pleural fold distinctly separates the anepisternite from the anepimerite and the catepisternite from the catepimerite. Matsuda $(1970,1976)$ gave an excellent theoretical synthesis of the main works on the fundamental pattern of the thorax of hexapods, following the subcoxal theory. In a previous paper, I retained homologies between the anapleuron and the precoxa, and between the catapleuron and the subcoxa (Deuve 2001a). In this model, two segments more proximal than the coxa are then present at the base of the hexapodan appendage. More recently, Kobayashi (2017) showed that the subdivision of the subcoxa into two segments can be observed during the embryonic development of Coleoptera, Megaloptera, Neuropterida and Trichoptera. In hemimetabolan orders, the differentiation of the paracoxal fold is more difficult to detect (e.g. Mashimo \& Machida 2017), but it has been observed at the imaginal stage in several orders (DuPorte 1965) and confirmed for the embryonic stage by Y. Kobayashi (personal communication). However, partly taking into account the remarks of Mashimo \& Machida (2017), Y. Kobayashi (personal communication) considers that both the anapleural and catapleural rings are subdivisions of the "subcoxa 2", and thus correspond to the true subcoxa, whereas the "subcoxa 1", as observed in several insect embryos, is a true proximalmost segment of the limb, located at the border with the tergum or paranotum.

This model of three basal segments of the hexapodan appendage (i.e. from most proximal to most distal: precoxa, subcoxa and coxa) fits perfectly with the theoretical model of the interpretation of the crustacean protopodite, which would also be three-segmented (from proximal to distal: precoxa, coxa and basis), bearing in mind that the crustacean coxa is homologous with the hexapodan subcoxa and the basis is homologous with the hexapodan coxa (Hansen, 1893) (Figure 2). Hansen (1893, p. 198) was the first author to describe in Argulus a trisegmented protopodite for the biramous swimming limb of Maxillopoda. In addition, the precoxa seems to belong to both the crustacean groundplan (Hansen 1925; Boxshall 2004) and the hexapodan groundplan (Sharov 1966; Boxshall 2004). Boxshall (1997) reported it in Remipedia and Maxillopoda. It was long considered to be present in Malacostraca (e.g. Hansen 1925) and in Stomatopoda (Balss 1938). Vandel (1949) pointed out that this trisegmentation is not primitive, but derived from secondary divisions of a primordial coxa. Recent studies of embryonic development confirm this view, but do not call into question the fundamentally trisegmented nature of the protopodite, probably common to all arthropods, although this hypothesis is still disputable (Bitsch 2001).

In a previous work (Deuve 1994, p. 203-204), I was already speculating that the paranotal lobes of the Arthropoda were pleural in nature and I compared those of the campodeiform larvae of certain Coleoptera to those of amphipods or isopods such as Saduria entomon. In the same vein, Y. Kobayashi (personal communication) recently drew my attention to the coxal plates of some amphipods and isopods, whose embryonic development has been accurately studied. In the late embryo of Orchestia (Pericarida), these plates are flap-like and mobile along the margin of the tergum, and they seem to form part of the limb (Ungerer \& Wolff 2005). In Porcellio (Oniscidea), they are still distinct but merge with the tergum and retain a shape like a 'paranotal lobe' (Wolff 2009). In the light of these different morphologies observed in crustaceans, the narrow anatomical relations between the precoxa and the paranotal lobe will have to be more accurately analysed in Hexapoda in order to understand the tergopleural territories and their respective links with the base of the limb and the true tergum.

The pleural regions of Myriapoda and Hexapoda have often been compared (e.g. Füller 1963a,b) and they offer evident similarities, related to terrestrial life, that might be homologies. In particular, two concentric sclerite rings at the base of the locomotory limb seem to belong to the myriapodal groundplan and would correspond to the two proximal true-segments, which Bäcker et al. (2008) named eupleurite and trochantinopleurite, partly following Crampton's (1914) terminology and Weber's (1933) view. In the same vein, Wesener et al. (2014) pointed out that in Diplopoda the spiracle-bearing plates previously interpreted as sternites were not of a sternal nature, but were instead subcoxal sclerites associated with the apparent limb base. Bäcker et al. (2008) gave a reasoned description of a possible evolution of pleural structures in Myriapoda and Hexapoda. 


\section{The subcoxal theory applied to abdominal segments}

Because the abdomen of the Hexapoda does not bear multisegmented locomotory limbs, it is more difficult to interpret its skeletal pattern. Few studies refer to the presence of the subcoxa and precoxa on this tagma. However, ventral sclerites (= ventrites) are classically interpreted as 'coxosternites', referring to the integration of some eupleural elements merged with the genuine sternum, and some abdominal pleurites have often been described, more or less associated with the spiracles (see e.g. the pleurites in Figure 11, named "epipleurites"). Bitsch (1994, p. 120) rightly interpreted the pleural sclerites of the abdomen as "arising from a basal appendicular segment (subcoxa) secondarily incorporated into the body wall". In this interpretation, we can stress a fundamental dissociation between the ventral component of the subcoxa, which is part of the coxosternum, and the more isolated dorsal component, which is embedded into the more laterodorsal body-wall and is often named 'pleurite'. A distinction is also made between the pregenital abdomen (segments I-VII), the appendages of which are rudimentary or absent, and the genital/post-genital abdomen (segments VIII-XI), some segments of which may carry visible appendages in the form of complex external genitalia (segments VIII and IX of female, segment X of male) and cerci (Bitsch 1979). In particular, the genital segments often carry a pair of gonopods, which are sometimes connected to the tergum by an articular pleurite. The interpretation of these structures is easier in females, whose ovipositor apparatus has sometimes retained its original metameric arrangement and its original connections with the tergum, which is not the case in males.

Recently, embryological studies have made it possible to identify the first buds of limbs and hence determine homonomies between thoracic and abdominal segments by serial comparison. Thus, Komatsu \& Kobayashi (2012) and Kobayashi et al. (2013) have identified in Coleoptera the "subcoxa 1" and "subcoxa 2", which can respectively be interpreted as the precoxa and subcoxa, more dorsal than the coxa, on the thoracic segments and abdominal segments I-VIII (Figure 3). These authors correctly presented their results as a contribution to the subcoxal theory (see also Kobayashi 2017).

Kobayashi et al. (2013) demonstrated that the epipleurite of the campodeiform Carabus larva corresponds to the subcoxa (subcoxa 2), whereas the juxta- or peri-spiracular area corresponds to the precoxa (subcoxa 1). In so doing, they showed that the 'epipleural field' I had identified and illustrated (Deuve 2001a) is actually a subcoxal territory (or, in some cases, subcoxal + precoxal). I fully agree with this interpretation, which makes my scheme of the hexapodan abdominal segments more coherent.

Just as the dorsal part of both subcoxa and precoxa are integrated into the lateral wall of the thoracic segments, with a function of fixation of the appendage to the body, the epipleurite is also integrated into the wall of the abdominal segments, but it remains distinct from the coxosternum (with which it may, however, merge in some cases) on the pregenital segments, and it has the same function of fixation of the appendage on the genital segments. By homonomy, these territories have the same identity, as well as the same functional specialisation. In general, the skeletal organisation of the thoracic and abdominal segments is thus homogenous. A study of the cephalic segments will probably show a similar pattern, with dorsal precoxal and subcoxal areas embedded into the body-wall. Precoxa and subcoxa tend to lose their appendicular morphology, but remain functionally associated with the protruding part of the limb, for which they provide anchoring, support and articulation.

In addition, we must keep in mind that if epipleural areas are subcoxal in their nature, they are truly appendicular and must therefore have a corresponding ventral part that is associated with the formation of the secondary sternum. This is precisely what Kobayashi et al. (2013) observed in the embryo.

In my 2001 paper, I showed that the epipleural areas participate in specialisation of the genital segments by serving as a substitute for the internalised subcoxosternum (formation of the vaginal ducts) through a medio-ventrad shift. This process of ventral closure of the genital segments, starting 
from the primitive seripleural type, leads to the formation of a sympleural abdomen (the epipleurites, of a subcoxal nature, join and merge ventrally) (Figure 4). In a way, this is the formation of a 'tertiary sternum'. In the 'sympleural-I' type the eighth epipleurites merge and participate in the formation of a 'subgenital plate', while gonopods VIII move rearwards to form a functional ovipositor in association with gonopods IX. In the 'sympleural-II' type, the eighth epipleurites form the first subgenital plate, but the ninth epipleurites also merge together to form a second subgenital plate, while the gonopods are no longer visible. The resulting secondary gonopore is then displaced to the rear of segment IX.

The primitive (plesiomorphic) seripleural type is present in Archaeognatha, Zygentoma, Dictyoptera and Dermaptera, as well as some exceptional coleopterans belonging to the genus Eustra, which have retained a neotenic abdominal structure (Deuve 1993, 2001b) (Figure 5). The sympleural-I type is present in Odonata, orthopteroids, Hymenoptera, Neuropterida, Coleoptera and Diptera; the sympleural-II type occurs in Trichoptera, Lepidoptera and Mecoptera (Deuve 2001a). However, it should be noted that the condition in Mecoptera is peculiar. The most plesiomorphic type of external genitalia occurs in Nannochoristidae, apparently corresponding to the sympleural type II, but the female gonopore is located at the rear of segment VIII rather than at the rear of segment IX (Mickoleit 1975). In the other families, an apparent second subgenital plate is produced by elements that would belong to the eighth segment ("coxosternites VIII") but are apparently located on segment IX, while the true epipleurites IX ("coxosternites IX") regress and finally disappear (Mickoleit 1975). Bitsch (1979), however, did not adopt this interpretation. In addition, a "genital chamber" is formed at the level of the segments VIII and IX, which contains vestiges of the gonopods on its inner surface (Grell 1942), as discussed and critised by Mickoleit (1976).

The best argument in favour of this seripleural and sympleural-type model is that there are no combined structures: the seripleural type, with retained metamerism, precludes the presence of a genuine subgenital plate when the vaginal duct is formed; the sympleural-II type, with a second subgenital plate, is incompatible with the presence of a true ovipositor. However, a problematic aspect of my interpretation was the structure of the genital segments in some females of Mecoptera. Mickoleit (1975) recognised the absence of the genuine sternites VIII and IX as a result of the morphogenesis of the genital chamber. He also described the presence of a small "laterotergite" lying near the spiracle of the pregenital segments, but also on segment VIII, where it is adjacent to the subgenital plate. Kristensen \& Nielsen (1999) considered this to be an argument against my interpretation of the epipleural nature of the ventral sclerites VIII. The same difficulty arises with Embioptera, which also have "laterotergites" in addition to the epipleurites (Klass \& Ulbricht 2009). However, as I have previously explained (Deuve 2001a), the 'laterotergite' of some Mecoptera is located beside the spiracle and not below it, as is usually the case for an epipleurite. In fact, if we consider that the epipleurite represents the dorsal part of the subcoxa, it is likely that the small socalled 'laterotergite' of segment VIII in some Mecoptera would be precoxal, ocupying same juxtaspiracular location as this sclerite in the larva of Carabus (Kobayashi et al. 2013). A similar situation is found in Neuropterida. Liu et al. (2016) admitted that "the predominant sternite-like sclerite of the female abdominal segment VIII represents the fused gonocoxites VIII" (it is actually formed from the merged epipleurites VIII). However, this subgenital plate is separated from the tergite by a fairly large membranous area containing the spiracle (Liu et al. 2016, "Fig. 12"). This area would represent a large part of the dorsal precoxal territory. The same situation can be observed in Coleoptera, but the dorsal part of the subcoxa (epipleurite) and of the precoxa may merge together, or merge with the tergum and even with the coxosternum or with the subcoxosternum such as in segment VIII of certain Scarabaeoidea (Ritcher 1969), or on the contrary become subdivided to allow increased mobility of the pregenital abdomen, as in Staphylinidae (Naomi 2014).

It should be noted that a sclerification does not necessarily follow the limits of the different anatomical fields. For example, among beetles, the epipleurite is located below the spiracle in Carabidae larvae, but the spiracle lies in the centre of a large sclerite (epipleurite + precoxite?) in certain larvae of Lampyridae (Deuve 2001a, "Fig. 6 and 7"). It is also well known that spiracles may move, some may disappear and yet others may appear, in the evolution of hexapods, especially in the most exobasal orders, such as the Diplura (see discussion in Kristensen 1997, and in Klass \& 
Kristensen 2001). Their location is certainly less variable in the pterygotes, where the location of the spiracular line can reasonably be used as landmark. Ritcher (1969) documented the migration of abdominal spiracles in some Scarabaeoidea (Coleoptera), but it is mainly the areas of sclerification of the abdominal wall that differ, depending on whether they are covered and protected by elytra or, in contrast, exposed to the environment. As Snodgrass (1935b, "Fig. 2") clearly illustrated, the location of the spiracular line can appear to be variable in different orthopteran families, but it is actually the areas of sclerification of the abdominal segments that have moved: in Tettigidea and Rhipipteryx the spiracle lies in the pleural membrane, whereas in Melanoplus it is located on the lateral margin of the so-called 'tergite', which apparently includes tergum + merged precoxae. Recently, Mashimo \& Machida (2017) showed that in Gryllus bimaculatus the subcoxa remains undivided during embryonic development and the spiracle appears on the lateral margin of the so-called tergum. Thus, the precoxa cannot be seen - there is only a 'paratergal furrow', which is a simple, not very evident linear depression that delimits the paranotal lobe bearing the spiracle. It is questionable whether the differences between the observations of Kobayashi et al. (2013) of the Carabus embryo and those of Mashimo \& Machida (2017) in a Gryllus embryo are due to artefacts produced by the techniques used, or whether they are instead real differences between the organisms. In fact, the buds and territories observed on a given embryo are already partly dependent on the future morphology of the imago, being precursors of the latter. That is a very general rule in any development process. In many orthopterans, spiracles are located on the apparent tergite (e.g. see above concerning the abdominal segments in Melanoplus). In this case, it is not unexpected that the same structure can be observed at an earlier embryonic stage of development.

Alternatively, one might try to retain the hypothesis of Mashimo \& Machida (2017) and consider a tergal (or, more exactly, tergopleural) origin of the spiracle-bearing territory. In this case, the "subcoxa 1" described by Kobayashi et al. (2013) in Carabus, apparently homologous with the 'tergal' territory observed in a Gryllus embryo, would also be of a tergopleural nature and could not be interpreted as the precoxa. The problem with this hypothesis is that it contradicts the formation of this "subcoxa 1" through a division of the primordial subcoxa observed by Kobayashi et al. (2013) during the embryonic development. It must be recognised that the problem of anatomical relationships between the spiracle and the lateral margins of the 'tergum' in hexapods is not yet resolved. For example, the anatomical studies of François (1996) on proturans clearly indicate the presence of spiracle much more dorsal than the anapleurite and located on the lateral margin of the so-called tergum (Figure 1). Another example amongst many others is that of the embryo of Pedetontus (Archaeognatha), in which the spiracles appear to be located on the margins of the so-called tergum (Machida 1981). The informative work of Niwa et al. (2010) on the latter illustrates the complex genetic relationships controlling the morphogenesis of both paratergal and limb territories.

In papers on Hemiptera, Sweet noted the presence of a double row of abdominal sclerites, which he named "laterotergites" (Sweet 1981), more or less following the terminology of Dupuis $(1949,1953)$. Later, he interpreted them as genuine pleurites, which he called hypopleurites and epipleurites (Sweet 1996), using the terminology of Hopkins (1909) also adopted by Deuve (1994). According to Sweet, these pleurites would form part of the fundamental organisation of the insect abdomen. It should be noted that in Heteroptera, it is the 'hypopleurite' in Sweet's sense, not the epipleurite, that bears the spiracle. This in turn raises new questions.

The fundamental pattern of insect abdomen has been illustrated by diagrams that explain the specialisation of the female genital segments with internalisation of the subcoxosternal plates (Deuve 2001a). These diagrams are reproduced here with slight modifications. Figure 4 illustrates the three abdominal types occurring in female insects: seripleural, sympleural-I and sympleural-II. A precoxite (i.e. precoxal sclerite) is figured next to the spiracle.

In my first attempt to introduce a particular sclerite, the "epipleurite", in the groundplan of the hexapodan segment, I mentioned the following homology: "to be cited as an example among other structures, the 'gonangulum' of Scudder (1957), which would correspond to the epipleurite of the IXth abdominal segment" (Deuve 1994, p. 203, translated from French). Indeed, the interpretative model 
proposed there makes it possible to understand the nature of the gonangulum, which corresponds to the epipleurite IX (Deuve 1994; 2001a, p. 210-211). In sympleural-I type, the gonangulum is a more or less triangular sclerite that has retained its articular function, connecting the ovipositor (gonopods VIII and IX) to the ninth tergite. In sympleural-II type, the gonangulum does not have this articular function because the epipleurite IX is a component of the second subgenital plate. This explains why Scudder (1971) pointed out the so-called 'absence' of a gonangulum in Mecoptera, Diptera, Trichoptera, Lepidoptera and Coleoptera. In the case of Coleoptera, the abdomen of females indeed belongs to the sympleural-I type, but gonopods VIII are reduced and closely associated with gonopods IX, so that there is no typical ovipositor and the epipleurites IX (gonangula) are, in contrast, strongly developed and do not look at all like 'small triangular articular sclerites'. The gonangulum has sometimes been confused by coleopterists with the lateral extremities of the so-called "tergum IX" expansions (Bils 1976; Burmeister 1976), following the interpretation of Mickoleit (1973). More recently, Hünefeld et al. (2012) interpreted the holometabolan groundplan as lacking the gonangulum, but I do not share this view. Simply, this epipleurite IX no longer has the morphological and functional appearance of a gonangulum as described by Scudder.

In a recent and meticulous work on the gonangulum, Klass et al. (2012) have presented an interpretation that is the same in its broad lines as the one I had previously developed (Deuve 1994, 2001a), but using the term laterocoxite (Bitsch 1973b, 1974) instead of epipleurite. In a study of the blattarian ovipositor, Klass (1998) had rightly compared the structure observed with that known in Archaeognatha, which led him to compare the gonangula, visible in the eighth and ninth segments, with the laterocoxites described by Bitsch in machilids. Later, in successive works on the abdomen of other exobasal hemimetabolan orders, notably Dermaptera, Klass $(2001,2003)$ was progressively led to generalise the term laterocoxite. Bitsch has named "laterocoxite" a small angular scleritesometimes visible in the genital segments of certain Archaeognatha, more rarely in the pregenital segments, and sometimes merged with the coxa-, that was already known as the "subcoxa" (Bekker 1925), the "laterosternite" (Gustafson 1950) or "laterotergite IX" (Livingstone, 1968), and which Smith (1969) had correctly interpreted as the subcoxa, independently of the older study by Bekker (1925). Bitsch proposed an identity of this sclerite with the piece named gonangulum by Scudder $(1957,1961 \mathrm{a}, \mathrm{b}, 1964,1971)$ and, at the same time, he suggested that it has probably a subcoxal nature. I also wrote about the laterocoxite as described in female machilids: "If this 'laterocoxite' corresponds to Scudder's gonangulum, as Bitsch suggested, it would be an epipleurite" (Deuve 2001a, p. 219). Thus, the link is established and we reach a consensus: Gustafson's (1950) laterosternite (described on the genital segments of female machilids, but misinterpreted because it is non-sternal), Scudder's (1957) gonangulum (described only in segment IX of the abdomen of some female insects), Bitsch's (1973b) laterocoxite (described on the genital segments of female machilids and correctly interpreted) and Hopkins' (1909) epipleurite (described on the abdominal segments of imagos and larvae of both sexes in coleopteran), are one and the same fundamental sclerite of the hexapodan segment, having a subcoxal nature. In this context, it should be noted that Bekker (1925) was the first author to correctly interpret epipleurite IX as the subcoxa in machilids (Archaeognatha), lepismatids and nicoletiids (Zygentoma), as well as in Gryllidea (Bekker 1932a,b).

This consensus might be extended further: Kukalová-Peck (1983, 1987, 1992, 1997, 2008) proposed an original model of the structure of the insect segment and limb based on study of some Carboniferous fossil hexapods. I published (Deuve 2001a, p. 220-221) a severe critique of this model because, in my opinion, Kukalová-Peck confused the epipleurite with the subcoxa. However, if we now consider that the epipleurite does indeed have a subcoxal nature, then Kukalová-Peck's model would regain part of its relevance. For this author, the hexapodan limb is composed of several segments integrated into the lateral wall, these being (from the most dorsal to the most distal): epicoxa (archipleuron), subcoxa, coxa and trochanter, followed by the multisegmented telopodite. KukalováPeck's model, based on compression fossils, the study of which is very delicate, can still be criticised. Shortcomings worth noting are: the subalar and basalar thoracic sclerites are claimed to be subcoxal (1983, p. 1652), the segment ("epicoxa") described as the most proximal is confused with the paranotal lobe (for this reason, the "epicoxa" of Kukalová-Peck, located above the spiracle, is not 
really synonymous with the precoxa), the subcoxa described by Kukalová-Peck on the abdomen lies near the spiracle and resembles the precoxa, the trochanter is dissociated from the telopodite. In fact, it is clear that in most of her illustrations - notably the diagrammatic representation of the typical segment of a protoinsect (Kukalová-Peck 1983, "Fig. 4") or the representation of a dipluran ("Fig. 7") or a paleodictyopteroid ("Fig. 1") - this author displaces all respective segments of the appendage. This results in the "epicoxa" at the location of the paranotal lobe, the "subcoxa" at the location of the precoxa, the "coxa" at the location of the subcoxa, and the "trochanter" at the location of the coxa. It should also be noted that the term "epicoxite" can hardly be adopted for the precoxa or paranotal lobe, because it has already been used by Becker (1924) and Füller (1963a) in a completely different sense: it designates a sclerite of a subcoxal nature in Myriapoda. The more precise study by Kobayashi et al. (2013) on a campodeiform Carabus larva demonstrates the location of the precoxa ("subcoxa 1") on the ventral flank of the paranotal lobe next to the spiracle (Figure 6a). This close association of precoxa and paranotal lobe evokes Rasnitsyn's (1981) model of a dual origin-paranotal and appendicular - of the wing of pterygotes (see also Niwa et al. 2010; Prokop et al. 2016; Elias-Neto \& Belles 2016; Mashimo \& Machida 2017). Kukalová-Peck (1978), inspired by the paper of Wigglesworth (1973), considered the wing as an exite of her "epicoxa". This idea of a wing originating from an exite (of the precoxa?) was taken up in developmental genetic studies (Averov \& Cohen 1997).

In a recent study of the postabdomen of Odonata, Klass (2008) pointed out the presence of a gonangulum (epipleurite IX) divided into two distinct sclerites, which he named "antelaterocoxa" and "postlaterocoxa". He homologised the former with Bitsch's (1974) "precoxite" and the latter with Bitsch's "laterocoxite". It should be noted in this respect that Bitsch (1974, p. 102, footnote) had taken care to specify that his term "precoxite" was purely descriptive and in no way referred to a presumption of precoxal nature. Emeljanov (2014) used Klass' observation to give the gonangulum a fundamentally dual nature, with "sternal" and "pleural or pleuroparatergal" components. The question of the identity of the antelaterocoxa in Odonata still deserves scrutiny, but Klass' (2008) interpretation of a gonangulum with either one-piece or bipartite condition sounds as corresponding to the nature of epipleurite in either subcoxal or subcoxal + precoxal identity. While awaiting precise analyses, it is important to assume that an epipleurite, in its current broad sense, may include a precoxal component, often merged with the subcoxal one. This is consistent with the delineation of the epipleurite as initially given by Hopkins (1909).

The present interpretation of the limb with a protopodite composed of three segments (precoxa, subcoxa and coxa) seems coherent. A subsidiary problem is presented by the coxa of the female gonopods, which sometimes appears to be bi-segmented. In Coleoptera, the gonopod IX is often (primitively?) composed of two segments, followed by the so-called stylus that is presumably of a telopodal nature (Deuve, 1993) (Figure 6b,c). Following Mickoleit (1973) and Bils (1976), Hünefeld et al. (2012) reported the existence of these two joints as "a cranial element of gonocoxite IX articulating with the laterotergite IX [what I named epipleurite IX], and a caudal element bearing a stylus". In his most recent studies on adephagans, Ball names these joints "gonocoxite 1" and "gonocoxite 2", i.e. coxa 1 and coxa 2 respectively (e.g. Ball \& Shpeley 2005). The question arises as to whether coxa 2 might be the trochanter, which has become well developed and adapted for oviposition in soil. In this case, the more distal so-called stylus in coleopterans would be the second segment of the telopodite, not the first. However, this idea is still speculative and lacks support. One might think that, quite simply, the coxal segment is dimeric in some coleopterans, showing a kind of annulation found in limb structure of many arthropods (Boxshall 2004), but it is noticeable that some muscles connect the basal joint to the distal one (Bils 1976). In addition, this bi-segmented structure is known in Hymenoptera and, according to Mickoleit (1973), it would belong to the groundplan of the Holometabola. It should also be noted that the gonopods VIII of certain Pygidicranidae (Dermaptera) have been described as bi-jointed (Deuve 2001a, "Fig. 28"; Klass 2003, "Fig. 68-69"), but they would be gonapophyses. 


\section{Rearward displacement of the gonopore}

Epitopy is the apparent rearward displacement of the gonopore as a result of the internalisation of subcoxosternal areas involved in formation of the ectodermal genital ducts. This term means that it is not, strictly speaking, a rearward migration of the gonopore, but rather an 'epitopic location' of it, i.e. peripheral in relation to the whole invaginated area forming the genital pouch, the protovagina and finally the vaginal duct. In females, a location of the secondary gonopore at the rear of segment VIII, or even at the rear of segment IX, is observed in most pterygotes. In contrast, gonopore orthotopy corresponds to the primitive condition, in which the primary female gonopore lies at the posterior margin of segment VII, corresponding to its original metameric position. True orthotopy has been reported in Archaeognatha, Zygentoma and, very exceptionally, in partially neotenic Coleoptera belonging to the genus Eustra (Deuve 1993, 2001a). I have mentioned elsewhere (Deuve 2001b) that a subterranean life may lead to partial neoteny, in relation to environmental stability (Gould, 1977), and this may reveal some primitive patterns by prematurely stopping the morphogenetic process of the organ concerned. In the case of the genus Eustra, it is the internalisation process of the subcoxosternal plates VIII and IX that has been prematurely halted during its development.

The apparent morphogenetic shift of the female gonopore during pre-imaginal development has been studied by several authors, especially Singh-Pruthi (1924), Heberdey (1931) and Metcalfe (1932a,b). Snodgrass (1933), Weber $(1933,1966)$ and Vandel (1949) published useful overview, but they used the diagrams of Heberdey, which are misleading. Indeed, there is no internal connection between three genital pouches, which are located, respectively, at the rear of sterna VII, VIII and IX, but there is a concomitant invagination of the subcoxosternal areas VIII and IX. Styš (1959) well understood this formation of a "gynatrium" by "invagination of the ventral portions of the VIIIth and IXth urites".

Figure 7 illustrates the location of the gonopore ("gon.") and its epitopy as a result of the ventral connection of the epipleurites VIII and epipleurites IX in sympleural types I and II, respectively. It should be noted that under these conditions the invaginated 'sternal' areas correspond to the secondary sternum and, necessarily, include some ventral components of the subcoxa and precoxa (but not the coxal ones, which correspond to the gonopods). These are therefore subcoxosternal areas (and even, as it should be written, precoxal-subcoxosternal). In the case of the sympleural-II type, the gonopods themselves have regressed and could have part of their territory included in this invagination. Thus, the secondary genital ducts (vaginal ducts) of insects are not only sternal, but subcoxosternal or sometimes coxosternal in nature. These considerations need to be taken into account in any study of the musculature supporting the ectodermal genitalia. On the other hand, the anatomical delimitation of these internalised territories is hardly possible in the current state of our knowledge (Figure 8). However, on the vaginal duct or bursa copulatrix of some Adephaga (Coleoptera), Bils (1976) was able to distinguish territories connected by muscles to segment VIII and others connected by muscles to segment IX: the former, ventral, are connected to epipleurites VIII, the latter, dorsal, lateral or caudal, are connected to epipleurites IX or, more rarely, to tergite IX or coxae of the ninth segment.

It is interesting to note that formation of the arthropod hypopharynx, which is ectodermal, follows a similar process, with participation of several cephalic segments and invagination of their respective subcoxosternal or sternal areas. The formation of the stomodeum, which is possibly comparable, has been interpreted in a variety of different ways (see review in Bitsch 1973a). In the same vein, the internalisation of the primary sternum in thoracic segments was clearly described and illustrated by Weber (1928) in context of the nascent "subcoxal theory".

It can also be noted that, in the same way as at the thorax the coxa maintains an articular function, remains associated with the prominent appendage but dissociates itself from the subcoxal territories which are embedded into the body, at the level of the genital segments the coxa remains associated with the gonopod of which it is a part, but dissociates itself from the so-called coxosternal 
plate, in reality subcoxosternal. This subcoxosternal plate includes only the ventral component of the subcoxa, not the dorsal component corresponding to the epipleurite, which is not internalised.

In the case of the insect abdomen, a crucial question is whether the whole subcoxosternum is internalised, or whether lateral margins of it could instead remain in their external position and participate partly in formation of the final subgenital plate in some cases. Just as thoracic subcoxosternal territories are more internalised in holometabolans than in hemimetabolans (Weber 1928; Ferris 1939), it can be supposed that the same is true for the subcoxosternal plates of the genital segments, the two processes probably being, in genetic terms, parallel. For example, Klass (2008) considers the ventrite VIII of the Odonata to be of a 'coxosternal' nature, but with inclusion of the epipleurites (which he names "laterocoxites"). This would therefore be, more exactly, an epipleurosubcoxosternum, because the coxae are excluded. The same author indicates that the embiopteran subgenital plate is atypical, being complex in nature and subject to interpretation in various hypothetical ways (Klass \& Ulbricht 2009).

In Coleoptera and certainly also in Neuropterida, which have very similar abdominal structures (Mickoleit 1973; Liu et al. 2016), it is clear that the totality of the subcoxosternal area is internalised because the two well delimited epipleurites are connected medio-ventrally to each other, are juxtaposed, and often even merge to form a kind of 'tertiary sternum'. In segment VIII, this merging of the epipleurites is sometimes so perfect that the resulting subgenital plate (of a strictly sympleural nature), named ventrite VIII, is still often confused by most coleopterists with 'sternite VIII' or 'coxosternite VIII', which is incorrect. The reality of the connection of the epipleurites is particularly well illustrated in the imaginal stage of certain Paussidae (Caraboidea), in which all intermediate steps can be observed between an orthotopic state-with the subcoxosternum still present between the epipleurites and the gonopore located at the rear of segment VII-and an epitopic state-with complete suturing of the epipleurites (Figure 9). Another argument is the presence in the genus Luperca (Caraboidea Siagonidae) of a membranous septum that connects the internal margins of the two epipleurites VIII to the gonopods VIII, which are associated with the ninth segment (Deuve 1988, 1993, p. 145, "Fig. 219"). The plesiomorphic presence of the gonopods VIII in their primitive location - between the two epipleurites VIII - is also observed in some Hydradephaga (Deuve 2001a, "Fig. 14"), whereas in other beetles they have become closely associated with gonopods IX to form an ovipositor and then regress. Concomitantly, the previously lateral epipleurites VIII become connected to each other ventromedially. [The following errors in Deuve (2001a) need to be noted: the references to figures "18" and "19" in the text (p. 207-208) should be corrected to 20 and 21 , and those to figures " 21 " and " 22 " in the text (p. 208), should be corrected to 18 and 19].

In many beetles, the merging of epipleurites VIII is perfect, such that the resulting ventral sclerite is identical in appearance to a coxosternite. In particular, strong longitudinal muscles are observed that connect ventrite VII to ventrite VIII. This point deserves special attention because it has often been used as an argument to interpret the ventrite VIII as being homonomous with the coxosternite VII. While it is true that muscle insertions can often be used as landmarks to delimit anatomical territories, this principle should not be applied dogmatically. For example, it was the presence of muscles directly connecting the tergum to the coxa that led Snodgrass $(1952,1958)$ to reject the subcoxal theory. In his study on the abdomen of female machilids, Bitsch (1973b) refers to the theoretical possibility of "a secondary displacement of the anterior attachment of the muscle 71" (translated from French). It is known that muscle insertions can actively migrate during development, especially during metamorphosis (Williams et al. 1984). Also, neoformations of muscles adapted to a new specialised function are frequent in insects. For example, Hünefeld et al. (2012) report the neoformation of a transverse muscle between appendages VIII of the Antliophora. The postabdominal musculature of the Adephaga (Coleoptera) was carefully studied by Bils (1976) and Burmeister (1976). In Hygrobia, there are muscles connecting epipleurite VIII to gonopod IX and other muscles connecting gonopod VIII to gonopod IX. These are functional specialisations related to the complex movements of the ovipositor. Also the muscles connecting epipleurites VIII to coxosternite VII in beetles are similar in shape and arrangement to the strong, ventral, antagonistic, longitudinal muscles 
that connect coxosternite VII to coxosternite VI, or coxosternite VI to coxosternite V. These are functional necessities related to the mobility of the whole abdomen and its ability to retract. The analogy of musculatures cannot be used to assert that ventrite VIII is the homonom of ventrite VII. A study of the abdominal muscles of female Paussidae (Caraboidea) beetles would have to be undertaken in the future to show, step by step, the muscular homologies and rearrangements between partially neotenic species of the genus Eustra which have an orthotopic gonopore and seripleural abdomen, and those belonging to other genera of the tribe Ozaenini, in which epipleurites VIII move closer to each other until they become connected and finally merge together to accompany the gonopore epitopy and to close the abdominal venter (Figure 9).

In Coleoptera, I showed that ventrites VIII and IX were formed by the suture or merging of the epipleurites in males as well (Deuve 1988). The differences are that gonopods IX of males are not visible on the ninth ventrite and that the aedeagus is mainly formed from segment $X$ (Dupuis 1950). The study of a gynandromorph of Cetoniidae (Coleoptera) showed the co-existence in the same specimen of the female (segment IX) and male (segment X) ectodermal genitalia, the latter located behind the former (Deuve 1992), thus providing evidence that they are not homologous. Ventrite IX, which has the misleading shape of an ordinary coxosternite in males (Figure 10f), is 'feminised' in this gynandromorph and shows some subdivisions that have the appearance of epipleurites and rudimentary gonopods (Figure 10e).

While it seems clear that ventrite VIII of Coleoptera (see Dupuis 2005, for Scarabaeoidea) and Neuropterida has arisen through the juxtaposition or merging of just the two epipleurites to form the first subgenital plate, without any subcoxosternal component, it is crucial to consider whether the same pattern could be generalised to all insects showing an abdomen of the sympleural type. Indeed, it is conceivable that in this type only a medial part of the subcoxosternum has been invaginated to form the genital ducts and that some lateral parts of it remain closely associated with the epipleurites. However, while the bipartite composition of ventrite VIII has often been documented in various orders, an obvious tripartite arrangement (i.e. with a median relictual subcoxosternal area) has never been reported.

In pterygote insects, it appears that the coxosternum of each abdominal segment forms an undivided ventral plate ( = ventrite), with only few examples of fragmentation being known. It can therefore be hypothesised that the entire genital subcoxosternal plate (i.e. in segments VIII and IX) is internalised when the vaginal ducts are formed. In contrast, the epipleurites are often well separated from the coxosternum. In many beetles, such as Stictotarsus or Systelosoma (Figure 11), the epipleurites are contiguous with the lateral margins of the coxosternite, but are not merged with it. Such a merging occurs in many pterygotes and we can refer to a resulting epipleuro-coxosternum occupying the ventral side of all pregenital segments of the abdomen. It appears important to insist on this anatomical and functional dissociation between the epipleurite on one side, and coxosternite on the other, on all abdominal segments. On the genital segments, the gonopods are dissociated from the subcoxosternum and therefore the epipleurites must a fortiori be dissociated. This dissociation is fundamental in the pterygote groundplan.

In female Coleoptera, Verhoeff (1918) had already pointed out the presence of a "bipartite sternite 8" and Tanner (1927) had written: "in some cases it [the VIIIth sternite] is shield-shaped and divided into two parts on the middle by a small strip of membrane". In female Mecoptera, the symmetrical bipartite nature of the ventrite VIII was noted by Mickoleit (1975), who admits the absence of the true sternum. Indeed, it is certainly in Mecoptera that this bipartite nature of ventrite VIII is most clearly visible. This author generalised this observation, writing: "Furthermore, we can assume that a larger sternal plate is lacking in the groundplan of the genital segments of the pterygotes" (Mickoleit 1975, p. 102, translated from German). However, in Mickoleit's model, which differs significantly from mine on this point, only the genuine primary sternum is internalised and the two remaining components of ventrite VIII retain the name "coxosternite VIII". Some students working with him, such as Bils (1976) and Burmeister (1976), also continued to use "coxosternite VIII" to designate the ventral sclerite of the adephagan beetles, whereas the 
homonomous ventrites IX are named by them, as by Mickoleit, "tergites IX" or "laterotergites IX". Mickoleit (ibid.) stated precisely: "Therefore, a true sternal plate would not exist at all at the venter of the 8th segment of the Pterygota. Whether and to what extent the subgenital plate of the pterygote groundplan is involved in the formation of the sclerites known as gonocoxosternites is not determined" (translated from German). After studying the postabdominal musculature in a nannochoristid (Mecoptera), Hünefeld \& Beutel (2011) have finally followed Mickoleit and concluded: "The ventral sclerotised parts of segments VIII and IX of mecopterid females (and endopterygote females in general) are derivatives of the genital appendages of these segments and definitively not true sternal sclerotisations". These so-called appendicular formations are subcoxal in nature and correspond to the epipleurites VIII and IX. In addition, this model can most likely be generalised to endopterygote males, as shown for coleopterans (Deuve 1988). But in my model, not only the primary sternum but the whole subcoxosternum is internalised and therefore absent from the external skeleton of the genital segments in both males and females of the endopterygotes.

Although the subgenital plate has often been interpreted as resulting from a rearward expansion of segment VII (see review in Bitsch 1979), Kristensen \& Nielsen (1999) wrote concerning the subgenital plate of an heterobathmiid (Lepidoptera): "While a derivation from the venter VII territory remains a possibility, it could also be a fusion product of the segment VIII appendage bases, as hypothesized for similar formations in the Mecoptera and Trichoptera (Mickoleit, 1975; Nielsen, 1980)". Although by 1999 the interpretation of these sclerites as being formed from only appendicular components was beginning to be accepted, Kristensen \& Nielsen (1999) referred to Mickoleit's model, with internalisation of the only primary sternum. It is also important to clearly distinguish between two different types of 'subgenital plates', which are not homologous and should not be confused. Posterior expansions of coxosternite VII to protect or support the genital segments are present in many insects and have sometimes been referred to collectively as the 'subgenital plate'. In Lepismatida, Rousset (1973) described a "languette" (small tongue-like lobe) which is a prominent membrane fold belonging to segment VII. In Coleoptera, ventrite VII is usually dilated rearwards to support the retracted postabdomen. This is not the typical subgenital plate of the sympleural-type abdomen, which consists of the two joined epipleurites VIII. Among hemimetabolan insects, the Dermaptera have a seripleural type abdomen (Deuve 2001a; Klass 2001, 2003), whereas the sympleural-I type is seen in orthopteroids. Their subgenital plate has been the subject of several studies without clear conclusions, probably because both kinds of 'subgenital plates' (expansion of coxosternum VII versus ventral junction of epipleurites VIII) have often been confused under this name. Qadri (1940), however, interprets the subgenital plate of Tettigonioidea as resulting from the fusion of lateroventral formations of the "sternite VIII" (read "ventrite VIII") which might be epipleurites. Snodgrass (1935b) indicates that the vaginal ducts of Locustana are formed from a medial groove along the entire length of the eighth ventrite during organogenesis. These observations are consistent, at least in part, with the hypothesis of a subgenital plate formed by the secondary juxtaposition of epipleurites VIII.

The abdomen of female Odonata has been well studied by Klass (2008) in a work that takes into account musculature and innervation. This author essentially agrees with my interpretation of the female genital abdominal segments (Deuve 2001a) by recognising in the same way the presence of epipleurite IX, which he names "laterocoxite IX", but with an anterior and posterior component. Regarding segment VIII, Klass (2008, p. 137) admits that the ventral plate VIII resembles the coxosternum of the pregenital segments, but in contrast to these the coxae VIII are not included. In such cases, it is reasonable to assume that the subcoxosternum VIII is also not included. However, in the same work Klass $(2008$, p. 117) rejects my interpretation of the ventral plate VIII as resulting from the medial merging of epipleurites VIII (his "laterocoxites VIII") for the sole reason that I named "coxosternum VII" the ventral sclerite of the preceding segments, which in my model would be "exclusively non-homonomous". That was not my opinion: in many pterygotes the epipleurites of the pregenital segments are indeed merged with the lateral margins of the coxosternum to form a single ventral sclerite. This is certainly the case in Mecoptera, judging by the musculature described by Hünefeld \& Beutel (2011) for the pregenital and genital segments, and probably also in Odonata. I agree that, in this precise case of Zygoptera, it would have been more accurate to use the full term 
'epipleuro-coxosternum VII' rather than 'coxosternum VII'. Instead, I opted for a simpler term, as was usual at that time. In addition, rearrangements of the musculature of the genital segments during metamorphosis are significant. A study by Matushkina (2008) on the transformation of the abdominal musculature of an aeshnid during metamorphosis shows the absence of several muscles of segment VIII in the imago, mainly "intersegmental sternal" and "intersegmental pleuro-sternal" muscles, in relation to the development of the internal and external genitalia. Conversely, these muscles remain present in the pregenital segments. Therefore, there is a considerable rearrangement of the ventral musculature of segment VIII, and even more so for segment IX. In a subsequent paper, Klass \& Ulbricht (2009) explicitly admitted a process of internalisation of the primary sternum of the genital segments in the introduction of their study of Embioptera: "the ventral plates of both segments 8 and 9 probably lack a sternal component, yet we call them coxosternites; and in cases of absence of discrete laterocoxites it is often disputable whether laterocoxal sclerotisations are absent or included in the coxosternite, and how large this portion is". However, I cannot follow these authors when they write a few lines earlier: "the laterotergites and perhaps also the pleurites fall into the category of epipleural sclerotisations as defined by Deuve (e.g. 2001)" (Klass \& Ulbricht 2009, p. 120). In fact, it is rather the "laterocoxite", as described in detail by Klass since his work on Dermaptera (Klass 2001), that most precisely corresponds to the epipleurite as I characterised and illustrated it in the fundamental structure of the insect abdomen in both sexes (Deuve 1994, 2001a, "Fig. 10 to 31"), its subcoxal identity being another question. The "laterotergites and pleurites" described by Klass \& Ulbricht (2009) in female embiopterans probably correspond to tergopleural and/or precoxal formations. Moreover, it is precisely this fundamental distinction between the epipleurite and a small sclerite (precoxite?) lying next to the spiracle that I pointed out (Deuve 2001a) in response to an objection from Kristensen \& Nielsen (1999) in their study of the subgenital plate of a heterobathmiid (Lepidoptera) (see above). That said, additional studies are still needed to assess the importance and limitations of the internalisation of all, or part, of the eighth subcoxosternum in Odonata and in other orders of hemimetabolan insects having a sympleural postabdomen. The question is whether the eighth ventrite consists only of the two connected epipleurites VIII - as I presume - or whether it may also retain some traces of the former subcoxosternum and, if so, in what proportion. However, if coxae VIII are not included in the eighth ventral plate of the Odonata (Klass 2008) and if a sternal component is also lacking in the Embioptera (Klass \& Ulbricht 2009), as in all pterygote insects (Mickoleit 1975), almost only the epipleurites VIII remain 'available' to form the subgenital plate. Coxal territories being absent (gonopods), the lateral margins of a subcoxosternite would theoretically be of a strictly subcoxal nature (ventral parts of the subcoxae). Therefore, at most, we could imagine some subcoxal remnants of the coxosternum which would then merge with the epipleurites to form a resulting tripartite or quadripartite subgenital plate that is totally subcoxal in nature. Yet nothing like this has ever been observed and it is not the simplest hypothesis. Except for a few details and the semantic replacement of the term epipleurite by laterocoxite, I finally see no fundamental difference between Klass's model and mine.

\section{Conclusions}

We have arrived at a fairly consensual model to describe the fundamental structure of the insect skeleton. In particular, the importance of the subcoxal area-not only on the thorax, but also on the abdomen - no longer seems to be in doubt. Named epipleurite (Hopkins 1909; Böving \& Craighead 1931; Deuve 1994; Sweet 1996), subcoxa (Bekker 1925, 1932a,b; Smith 1969) (in reality, only the dorsal part of the subcoxa, the ventral part being integrated into the secondary sternum), laterosternite (Gustafson 1950; Matsuda 1957), gonangulum (Scudder 1957, 1971) or laterocoxite (Bitsch 1973b, 1974; Klass 2001), a sclerite of a subcoxal nature has been identified at all segments of the abdomen, and in both sexes. The same applies to the cephalic segments, for which developmental genetic techniques have recently revealed subcoxal territories at the base of gnathal appendages (Coulcher et al. 2015). Also, I have stressed the dissociation, in anatomical and probably also genetic terms, between the dorsal part of the subcoxa, which corresponds to the epipleurite, and the ventral 
part, which is more closely associated with the primary sternum to form a coxosternum or a subcoxosternum.

It is noteworthy how much the existence of a subcoxa has been discussed for more than a century and that it has only recently been recognised in the mandible or on all segments of the abdomen. It might be concluded from this that this segment is cryptic, but this is not the case. On the contrary, it actually occupies a large area and has important functions in the patterning of the hexapodan skeleton. In the thorax, the subcoxa plays a major role in the formation of the secondary sternum and the lateral wall lying between the coxa and the tergum. In the abdomen, the subcoxa plays a similar role in the formation of a secondary sternum (coxosternum), but it also plays this role in the pleural regions below the spiracle and, on the genital segments, in the support and articulation of the gonopods and/or in the formation of a new ventrite (subgenital plate) that is a sort of 'tertiary sternum'. Whereas the coxa has acquired a predominant articular function during evolution, the subcoxa (and probably also the precoxa that originates from it) has become specialised for the functions of fixing the limb to the body-wall and carrying the appendage, while maintaining its relative mobility. This can be observed on the abdominal and thoracic segments, whose general architecture is finally quite similar. There is not only structural but also functional homonomy and identity.

The presence or absence of a precoxa at the base of the hexapodan appendage still remains a subject of discussion. There are good arguments to support the existence of this proximalmost segment resulting from a subdivision of the embryonic subcoxal bud, in agreement with the tri-segmented protopodite model of the crustaceans. The hypothesis of a precoxal segment is obviously crucial, particularly for understanding the anatomical origin of the wings of the Pterygota.

Some points still remain to be clarified. Whereas the hypothesis of the internalisation of the whole subcoxosternum in the genital segments of Holometabola seems to be firmly established, the possibility in hemimetabolan insects that some marginal subcoxosternal elements might remain external and, if so, in what proportions, still needs to be evaluated. Also, we have yet to identify the nature of certain small enigmatic sclerites, such as the "tergopleurites" described by Prell (1913) and the "laterotergites" described by François $(1964,1996)$ in Protura and by Bäcker et al. $(2008)$ in some Chilopoda. More importantly, the problem of the origin of wings in pterygotes needs to be clarified, in relation to the identity of the axillary sclerites. In a recent paper, Mashimo \& Machida (2017) stressed the difficulty in delineating the crucial anatomical boundary between the tergum and the arthropod appendage. The question of the fundamental location of the spiracle on the lateral margins of the socalled tergum or on the very base of the appendage remains wide open. These wing and spiracle problems are reflected in the abundant literature dealing with the pleura of arthropods for over a century. It may be questioned whether the intrinsic difficulty in locating this tergal/pleural boundary is related to an earlier appendicular nature of the lateral margins of the so-called tergum itself. As has already been pointed out (Deuve 1994), the dorsum of Euarthropoda is fundamentally trilobed (Lauterbach 1974) and it is consistent to suppose that paranotal lobes are tergopleural in nature, rather than being strictly tergal formations. Given that the ancestor of Euarthropoda was probably a type of marine worm, it seems likely that the ventral part of its pleura became specialised for locomotion on the seabed, whereas the dorsal part became specialised for respiration and gill protection. This same pleural origin of the base of the arthropodal limb and of the paranotal lobe would make it easier to understand their close functional (and genetic?) association, as well as the 'dual' origin of the wings of pterygote insects. Hopefully this speculative idea will be read with indulgence, but, after more than a century of debate and some probably excessive attempts at schematisation, it must be kept in mind that there is still much work to be done to fully clarify our understanding of the arthropod pleura. 


\section{Glossary of the main terms used:}

Appendage: Eupleural set corresponding to a specialised organ and consisting of several successive segments; in hexapods these are: precoxa, subcoxa, coxa, and telopodites. (Synonym: limb)

Coxosternum: Ventral sclerite corresponding to the merging of the true sternum, the coxae and some ventral components of the subcoxae. In theory, ventral components of the precoxae would also be included. The coxosternum, often termed "secondary sternum" in the context of the subcoxal theory, or just ventrite, is clearly visible as the only ventral sclerite of the pterygote pregenital abdominal segments. (Plural: coxosterna)

Dorsum: The dorsal face of the body (Audouin 1820). In theory, a sclerite of the dorsum would be a "dorsite", but this term is rarely used.

Epipleurite: (Hopkins 1909). Separated sclerite well visible in the skeleton of many arthropods, especially in pterygotes. It corresponds to the dorsal part of the subcoxa, which dissociates itself from the ventral part to remain in a pleural position between the base of the functional appendage and some more dorsal sclerites. It may also have a precoxal component. Conversely, the ventral part of the subcoxa tends to associate with the sternum to form a subcoxosternum or a coxosternum. However, the epipleurite can in some cases merge with the coxosternum. The epipleurite has often been referred to as "laterotergite" by Snodgrass, especially in his famous book "Principles of insect morphology" (1935a). The gonangulum of Scudder (1957) is the abdominal epipleurite IX (Deuve 1994, 2001a). The laterocoxite (Bitsch 1973b, 1974) might be a synonym of epipleurite.

Epipleuro-coxosternum: Ventral sclerite resulting from the merging of the epipleurites and the coxosternum. It is often observable on the pregenital abdominal segments of insects.

Eupleurite: (Crampton 1914). Pleural sclerite forming part of the arthropodal appendage.

Exobasal: (Deuve 2013, p. 5, footnote). In a phylogenetical tree, only an ancestor or a node (i.e. a cladogenetical event), or, at the limit, an entire lineage, may be said to be 'basal'; an extant clade branched basally is exobasal, but its most recent common ancestor is basal in the phylogeny of the group. Evidently, the sister-group of an exobasal clade is also exobasal. For example, Archaeognatha is an exobasal order of Hexapoda, which is not the case of Lepidoptera.

Paranotal lobe: Often considered as lateral lobes of the tergum, the paranotal lobes may be tergopleural formations (Deuve 1994). In the theory of the dual origin of the pterygote wing (Rasnitsyn 1981), they have become associated themselves with basal elements of the appendage (eupleural elements) to form the functional wing.

Pleuron: Lateral area located between the tergum and the sternum. A sclerite of the pleuron is a pleurite. (Plural: pleura)

Precoxa: The basalmost segment of the arthropodal appendage. Its existence is still under debate. It has been observed in crustaceans, myriapods and hexapods. It would correspond to the 'subcoxa 1'. A sclerite of the precoxa is a precoxite. (Plural: precoxae)

Sternum: Area located ventrally between the pleura, i.e. between the appendages. A sclerite of the sternum is a sternite. (Plural: sterna)

Subcoxa: Basal segment of the appendage (homologue of the coxa of crustaceans) located between the precoxa and the coxa. It corresponds to the 'subcoxa 2'. Often cryptic because embedded into the body-wall of arthropods (subcoxal theory), with a function of anchoring and supporting the appendage. The epipleurite corresponds to its dorsal component, which retains a pleural location and remains more or less isolated from the coxosternal plate (coxosternum). A sclerite of the subcoxa is a subcoxite. (Plural: subcoxae) 
Subcoxosternum: Ventral plate resulting from the merging of the true sternum and some ventral components of both the subcoxae and precoxae. The coxae are not integrated in it. It should be noted that the 'secondary sternum' of the pterygote thoracic segments is a subcoxosternum rather than a coxosternum, the two coxae being separated from it and functioning as articular segments of the appendages. Although they are often confused by authors, the distinction between subcoxosternum and coxosternum is essential, especially at the level of the abdomen, in order to fully understand the structure of sclerites of the pregenital segments on the one hand (with a coxosternum) and that of the genital segments on the other (with internalisation of the subcoxosternum). (Plural: subcoxosterna)

Tergopleurite: (Prell 1913). Pleural sclerite not strictly belonging to the arthropodal appendage. Located between the base of the arthropodal appendage and the true tergum.

Tergum: Area located dorsally between the pleura. A sclerite of the tergum is a tergite. (Plural: terga)

Venter: The ventral face of the body. A sclerite of the venter is a ventrite. (It should be noted that Snodgrass (1935a, 1963) considered the venter as synonymous with sternum and Styš (1959) the ventrite as synonymous with the epipleuro-coxosternum, which he named "zygosternum".)

\section{Abbreviations used in the illustrations:}

\author{
A1, $A 2 \ldots$ An: abdominal segments 1 to $\mathrm{N}$ \\ acc.gl.: accessory gland \\ aed.: aedeagus \\ ana: anapleurite \\ b.c.: bursa copulatrix \\ ba: basis \\ ca: carpus \\ cata: catapleurite \\ cx: coxa \\ cxst: coxosternum \\ $d$ : dactylus \\ def. $\boldsymbol{g l . :}$ defensive gland \\ ej.duct: ejaculatory duct \\ epl.: epipleurite \\ eppd: epipodite \\ exo: exite \\ fm: femur \\ fun.: funnel \\ gen.ring: genital ring \\ gon.: gonopore \\ gpd.: gonopod \\ is: ischium \\ lig.bas.: ligula basalis \\ lpnt: paranotal lobe \\ ltg: laterotergite \\ $\boldsymbol{m b}$ : membrane \\ mer: merus
}

oss: subapical setose organ (including the socalled stylus)

ov : oviduct

pcx: precoxa

pl: pleurite

pp: periproct

pr.: proctodeum

pro: propodus

prtvg: protovagina

ptar: pretarsus

scx: subcoxa

scxst: subcoxosternum

sp.: spiracle

sp.gastr.: spiculum gastrale

spm.: spermatheca

sty: stylus

subgen. pl.: subgenital plate

synscl.: synsclerite

T1, T2, T3: thoracic segments 1-3

tar: tarsus

tb: tibia

tg: tergum or tergite

tlpd: telopodite

tr: trochanter

v.: ventrite

vg: vaginal duct

vg. ap.: vaginal apophysis 


\section{Acknowledgements}

I am very grateful to the two reviewers, whose corrections and constructive comments were helpful for improving the manuscript, to Mark Judson (MNHN), who kindly corrected the English text, and to Jocelyne Guglielmi (MNHN), who found for me the little-known articles of Ernest Becker (or "Bekker").

\section{References}

Audouin V. 1820. L'anatomie comparative des parties solides des insectes. Annales générales des Sciences physiques. 7:396-406.

Audouin V. 1824. Recherches anatomiques sur le thorax des animaux articulés et celui des insectes hexapodes en particulier. Annales de Sciences naturelles ( $1^{\text {ère }}$ Sér.). 1:97-135, 416-432.

Averof M. \& Cohen SM. 1997. Evolutionary origin of insect wings from ancestral gills. Nature. (385):627-630.

Bäcker H, Fanenbruck M, Wägele JW. 2008. A forgotten homology supporting the monophyly of Tracheata: the subcoxa of insects and myriapods re-visited. Zoologischer Anzeiger 247:185207.

Ball GE, Shpeley D. 2005. Taxonomic review of the Tribe Melaenini (Coleoptera: Carabidae), with observations on morphological, ecological and chorological evolution. Zootaxa. (1099):1120.

Balss H. 1938. Stomatopoda, pp. 1-173, figs 1-114. In: Bronn HG, editor. Klassen und Ordnungen des Tierreichs. 5 (Abt. 1), Buch 6, Teil 2. Leipzig.

Barlet J. 1946. Remarques sur la musculature thoracique des Machilides (Insectes Thysanoures). Annales de la Société scientifique de Bruxelles. 60:77-84.

Barlet J. 1950. La question des pièces pleurales du thorax des Machilides (Thysanoures). Bulletin et Annales de la Société entomologique de Belgique. 86:179-190.

Barlet J, Carpentier F. 1962. Le thorax des Japygides. Bulletin et Annales de la Société entomologique de Belgique. 98:95-123, + 1 pl. h.t.

Becker E. 1924. Zur morphologischen Bedeutung der Pleuren bei Ateloceraten. Zoologischer Anzeiger. 60:169-185.

Bekker EG. 1925. K stroyeniyu i proiskhozhdeniyu naruzhnykh polovykh pridatkov Thysanura I Hymenoptera [Structure and origin of the external genital appendages of Thysanura and Hymenoptera]. Transactions of the Research Institute of the Moscow University. 1:157-206.

Bekker EG. 1932a. K evolyutsij naruzhnogo polovogo apparata nishikh Pterygota. Soobchenie 1. K stroeniyu I razvitiyu yajtseklada kuzhetsikovykh (Tettigonioidea). Zoologicheskij Zhurnal. 11 (Facsimile in Bekker 1966:296-316).

Bekker EG. 1932b. K evolyutsij naruzhnogo polovogo apparata nishikh Pterygota. Soobchenie 2. K razvitiyu yajtseklada svertskovykh (Gryllodea). Zoologicheskij Zhurnal. 11 (Facsimile in Bekker 1966:317-320).

Bekker EG. 1960. Evolution of the leg in Tracheata. Part 1. Subcoxal theory and a critique of it [in Russian]. Entomologicheskoe Obozrenie. 39:521-528.

Bekker EG. 1966. Teoriya morphologicheskoj evolyutsij nasekomykh. Moskva: Izdatelstvo Moskovskogo Yuniversiteta, $328 \mathrm{pp}$.

Bils W. 1976. Das abdomenende weiblicher terrestrische lebender Adephaga une seine Bedeutung für die Phylogenie. Zoomorphologie. 84:113-193.

Bitsch J. 1973a. Voies digestives céphaliques des Insectes, pp. 42-60. In: P.-P. Grassé, editor. Traité de Zoologie. 8, no1:1-799. 
Bitsch J. 1973b. Morphologie abdominale des Machilides (Thysanura) - I. Squelette et musculature des segments prégénitaux. Annales des Sciences naturelles, Zoologie. 12 $2^{\mathrm{e}}$ Ser., 15:173-200.

Bitsch J. 1974. Morphologie abdominale des Machilides (Thysanura) - II. Squelette et musculature des segments génitaux femelles. International Journal of Insect Morphology \& Embryology. 3:101-120.

Bitsch J. 1979. Morphologie abdominale des Insectes, pp. 291-600. In: P.-P. Grassé, editor. Traité de Zoologie. 8, no 2:1-600.

Bitsch J. 1994. The morphological groundplan of Hexapoda: critical review of recent concepts. Annales de la Société entomologique de France. 30:103-129.

Bitsch J. 2001. The hexapod appendage: basic structure, development and origin. In: Deuve T, editor. Origin of the Hexapoda, pp. 175-193. Annales de la Société entomologique de France. n.s. 37:304 pp.

Börner C. 1921. Die Gliedmassen der Arthropoden, pp. 649-694. In: Lang A., editor. Handbuch der Morphologie der wirbellosen Tiere. 4. Band. Arthropoda. Iena: Gustav Fischer Publ., 748 pp.

Böving AG. 1914. On the abdominal structure of certain beetle larvae of the campodeiform type. A study of the relation between the structure of the integument and the muscles. Proceedings of the entomological Society of Washington. 16:55-63.

Böving AG, Craighead FC. 1931. An illustrated synopsis of the principal larval forms of the order Coleoptera. Brooklin: Brooklin entomological Society, $351 \mathrm{pp}$.

Boxshall G. 1997. Comparative limb morphology in major crustacean groups: the coxa-basis joint in postmandibular limbs, pp. 155-167. In: Fortey RA. \& Thomas RH, editors. Arthropod relationships. Systematics Association special Volume, Series 55. London: Chapman \& Hall, xii $+383 p p$.

Boxshall G. 2004. The evolution of arthropod limbs. Biological Reviews. 79:253-300.

Bretfeld G. 1963. Zur anatomie und Embryologie der Rumpfmuskulatur und der abdominalen Anhänge der Collembolen. Zoologisches Jahrbücher, Anatomie. 80:309-384.

Burmeister EG. 1976. Der Ovipositor der Hydradephaga (Coleoptera) und seine phylogenetische Bedeutung unter besondere Berücksichtigung der Dytiscidae. Zoomorphologie. 85:165-257.

Carpentier F. 1946. Sur la valeur morphologique des pleurites du thorax des Machilides (Thysanoures). Bulletin et Annales de la Société entomologique de Belgique. 82:165-181.

Carpentier F. 1947. Quelques remarques concernant la morphologie thoracique des Collemboles (Aptérygotes). Bulletin et Annales de la Société entomologique de Belgique. 83:297-303.

Carpentier F, Barlet J. 1951. Les sclérites pleuraux du thorax de Campodea (Insectes, Aptérygotes). Bulletin de l'Institut Royal des Sciences naturelles de Belgique. 27:1-7.

Coulcher JF, Edgecombe GD, Telford MJ. 2015. Molecular developmental evidence for a subcoxal origin of pleurites in insects and identity of the subcoxa in the gnathal appendages. Scientific Reports. 5:15757. doi: 10.1038/srep15757.

Craighead FC. 1916. The determination of the abdominal and thoracic areas of the cerambycid larvae as based on a study of the muscles. Proceedings of the entomological Society of Washington. 18:129-146.

Crampton GC. 1909. A contribution to the comparative morphology of the thoracic sclerites of insects. Proceedings of the Acadademy of natural Sciences of Philadelphia. 61:3-54+4pls.

Crampton GC. 1914. Notes on the thoracic sclerites of winged insects. Entomological News. 25:1525.

Deharveng L. 1983. Morphologie évolutive des Collemboles Neanurinae en particulier de la lignée néanurienne. Travaux du Laboratoire d'Ecobiologie des Arthropodes édaphiques, Toulouse. $4, \mathrm{n}^{\circ} 2: 1-63$.

Denis R. 1949. Sous-classe des Aptérygotes (Apterygogenea, Brauer, 1885, Apterygota, Lang, 1889). Anatomie - Biologie - Systématique : pp. 111-275. In: P-P. Grassé, editor. Traité de Zoologie. 9:1-1117.

Deuve T. 1988. Les sternites VIII et IX de l'abdomen sont-ils visibles chez les imagos des Coléoptères et des autres Insectes Holométaboles? Nouvelle Revue d'Entomologie. n.s. 5:21-34. 
Deuve T. 1992. Origine segmentaire des genitalia ectodermiques mâles et femelles des Insectes. Données nouvelles apportées par un gynandromorphe de Coléoptère. Comptes rendus de l'Académie des Sciences, Paris. 314, sér. III:305-308.

Deuve T. 1993. L'abdomen et les genitalia des femelles de Coléoptères Adephaga. Mémoires du Muséum national d'Histoire naturelle, Zoologie. 155:1-184.

Deuve T. 1994. Sur la présence d'un "épipleurite" dans le plan de base du segment des Hexapodes. Bulletin de la Société entomologique de France. 99:199-210.

Deuve T. 2001a. The epipleural field in hexapods. In: Deuve T, editor. Origin of the Hexapoda, pp. 195-231. Annales de la Société entomologique de France (n.s.). 37:304 pp. [Erratum: Annales de la Société entomologique de France. n.s. 37[2001]:533]

Deuve T. 2001b. Le genre Eustra Schmidt-Goebel, 1846, Insectes (Coleoptera, Paussidae, Ozaeninae) à genitalia femelles orthotopiques. Zoosystema. 23:547-578.

Deuve T. 2013. Cychrus, Calosoma et Carabus de Chine. Sofia, Moscow: Pensoft Publ. 307 pp. [in French, partly in English]

DuPorte E M. 1965. The lateral and ventral sclerites of the insect thorax. Canadian Journal of Zoology 43:141-154.

Dupuis C. 1949. Données nouvelles sur la morphologie abdominale des Hémiptères Hétéroptères et en particulier des Pentatomoides, pp. 471-472. In: Caullery M, editor. XIII ${ }^{\mathrm{e}}$ Congrès international de Zoologie, Paris 1948.

Dupuis C. 1950. Origine et dévelopement des organes génitaux externes des mâles d'Insectes. Année biologique. 26:21-36.

Dupuis C. 1953. Les Rhopalidae de la faune française (Hemiptera, Heteroptera). Caractères généraux - Tableaux de détermination - Données monographiques sommaires. Cahiers des Naturalistes parisiens. 8:67-82.

Dupuis F. 2005. L'abdomen et les genitalia des femelles de Coléoptères Scarabaeoidea (Insecta, Coleoptera). Zoosystema. 27:733-823.

Elias-Neto M, Belles X. 2016. Tergal and pleural structures contribute to the formation of ectopic prothoracic wings in cockroaches. Royal Society open Science. 3:160347. http://dx.doi.org/10.1098/rsos.160347.

Emeljanov AF. 2014. The evolutionary role and fate of the primary ovipositor in insects. Entomological Review. 94:367-396.

Ferris GF. 1939. Some general considerations. In: Rees BE, Ferris GF. 1939.

Ferris GF. 1940a. The myth of the thoracic sternites of insects. Microentomology. 5:87-90.

Ferris GF. 1940b. The morphology of Plega signata (Hagen) (Neuroptera: Mantispidae). Microentomology 5:33-56.

François J. 1964. Le squelette thoracique des Protoures. Travaux du Laboratoire de Zoologie de la Faculté des Sciences de Dijon. no55:1-17.

François J. 1996. Squelette et musculature thoraciques des Protoures. Annales de la Société entomologique de France. 32:233-249.

Füller H. 1963a. Vergleichende Untersuchungen über des Skelettmuskelsystem der Chilopoden. Abhandlungen der deutschen Akademie der Wissenschaften zu Berlin, Klasse für Chemie, Geologie und Biologie. (1962) (3):1-98.

Füller H. 1963b. Die Bedeutung der Chilopodenmorphologie für die Subcoxaltheorie. Zoologischer Anzeiger. 170:176-187.

Gould SJ. 1977. Ontogeny and phylogeny. Cambridge (Massachussetts) \& London: Belknap Press of Harvard University Press, $501 \mathrm{pp}$.

Grell KG. 1942. Der Genitalapparat von Panorpa communis L. Zoologische Jahrbücher. Abteilung für Anatomie und Ontogenie der Tiere. 67:513-588.

Gustafson JE. 1950. The origin and evolution of the geniatlia of the Insecta. Microentomology. 15:35-67.

Hansen HJ. 1893. Zur Morphologie der Gliedmassen und Mundtheile bei Crustaceen und Insekten. Zoologischer Anzeiger. 16:193-198, 201-212. 
Hansen HJ. 1925. Studies on Arthropoda II. Copenhagen: Gyldendalske Boghandel, 176 pp. +8 pls h.t.

Hansen HJ. 1930. Studies on Arthropoda III. Copenhagen: Gyldendalske Boghandel, 376 pp. +16 pls h. t.

Heberdey RF. 1931. Zur Entwicklungsgeschichte vergleichende Anatomie und Physiologie der weiblichen Geschletsausführwege der Insekten. Zeitschrift für Morphologie und Ökologie der Tiere. 22:416-586.

Heymons R. 1899. Beiträge zur Morphologie und Entwicklungsgeschichte der Rhynchoten. Nova Acta der kaiserlich Leopoldinisch-Carolinisch deutschen Akademie der Naturforscher. 74:349-456.

Hopkins AD. 1909. Contributions toward a monograph of the scolytid beetles. I. The genus Dendroctonus. United States Department of Agriculture, Bureau of Entomology, Washington D. C., Tech. Ser. no. 17:57-64.

Hünefeld F, Beutel RG. 2011. The female postabdomen of the enigmatic Nannochoristidae (Insecta: Mecopterida) and its phylogenetic significance. Acta zoologica. 93[2012]:231-238. doi: 10.1111/j.1463-6395.2011.00551.x

Hünefeld F, Missbach C, Beutel RG. 2012. The morphology and evolution of the female postabdomen of Holometabola (Insecta). Arthropod Structure \& Development. 41:361-371.

Klass K-D. 1998. The ovipositor of Dictyoptera (Insecta): homology and ground-plan of the main elements. Zoologischer Anzeiger. 236:69-101.

Klass K-D. 2001. The female abdomen of the viviparous earwig Hemimerus vosseleri (Insecta : Dermaptera: Hemimeridae), with a discussion of the postgenital abdomen of Insecta. Zoological Journal of the linnean Society. 131:251-307.

Klass K-D. 2003. The female genitalic region in basal earwigs (Insecta: Dermaptera: Pygidicranidae (s.1.). Entomologische Abhandlungen. 61:173-225.

Klass K-D. 2008. The female abdomen of ovipositor-bearing Odonata (Insecta:Pterygota). Arthropod Systematics \& Phylogeny. 66: 45-142.

Klass K-D, Kristensen NP. 2001. The ground plan and affinities of hexapods: recent progress and open problems. In: Deuve T, editor. Origin of the Hexapoda, pp. 265-298. Annales de la Société entomologique de France. n.s. 37:304 pp.

Klass K-D, Matushkina NA, Kaidel J. 2012. - The gonangulum: a reassessment of its morphology, homology, and phylogenetic significance. Arthropod Structure \& Development. 41:373-394.

Klass K-D, Ulbricht J. 2009. The female genitalic region and gonoducts of Embioptera (Insecta), with general discussions on female genitalia in insects. Organisms Diversity \& Evolution. 9:115-154.

Kobayashi Y. 2017. Formation of subcoxae- 1 and 2 in insect embryos: the subcoxal theory revisited. Proceedings of the arthropodan embryological Society of Japan. 48:33-38.

Kobayashi Y, Niikura K, Oosawa Y, Takami Y. 2013. Embryonic development of Carabus insulicola (Insecta, Coleoptera, Carabidae) with special reference to external morphology and tangible evidence for the subcoxal theory. Journal of Morphology. 274:1323-1352.

Komatsu S, Kobayashi Y. 2012. Embryonic development of a whirligig beetle, Dineutus mellyi, with special reference to external morphology (Insecta: Coleoptera, Gyrinidae). Journal of Morphology. 273:541-560.

Kristensen NP. 1997. The groundplan and basal diversification of the hexapods, pp. 281-293. In: Fortey RA, Thomas RH, editors. Arthropod relationships. Systematics Association Special Volume Series. 55. London: Chapman \& Hall, xii + 383pp.

Kristensen NP, Nielsen ES. 1999. Heterobathmia valvifer n. sp.: a moth with large apparent 'ovipositor valves' (Lepidoptera: Heterobathmiidae). Steenstrupia. 24 [1998]:141-156.

Kukalova-Peck J. 1978. Origin and evolution of insect wings and their relation to metamorphosis, as documented by the fossil record. Journal of Morphology. 156:53-126.

Kukalová-Peck J. 1983. Origin of the insect wing articulation from the arthropodan leg. Canadian Journal of Zoology. 61:1618-1669. 
Kukalová-Peck J. 1987. New Carboniferous Diplura, Monura, and Thysanura, the hexapod ground plan, and the role of thoracic side lobes in the origin of wings of Insecta. Canadian Journal of Zoology. 65:2327-2345.

Kukalová-Peck J. 1992. The "Uniramia" do not exist: the ground plan of the Pterygota as revealed by Permian Diaphanopterodea from Russia (Insecta: Paleodictyopteroidea). Canadian Journal of Zoology. 70:236-255.

Kukalová-Peck J. 1997. Arthropod phylogeny and 'basal' morphological structures, pp. 249-268. In: Fortey RA, Thomas RH, editors. Arthropod relationships. Systematics Association Special Volume Series. 55. London: Chapman \& Hall, xii + 383pp.

Kukalová-Peck J. 2008. Phylogeny of higher taxa in Insecta: finding synapomorphies in the extant fauna and separating them from homoplasies. Evolutionary Biology. 35:4-51. doi: 10.1007/s1692-007-9013-4.

Lauterbach KE. 1974. Die Muskulatur der Pleurotergite im Grundplan der Euarthropoda. Zoologischer Anzeiger. 193:70-84.

Liu X, Lü Y, Aspöck H, Yang D \& Aspöck U. 2016. Homology of the genital sclerites of Megaloptera (Insecta: Neuropterida) and their phylogenetic relevance. Systematic Entomology. 41:256-286.

Livingstone D. 1968. On the morphology and bionomics of Tingis. Duddleidae Drake (Heteroptera: Tingidae). Part III - Functional morphology of the abdomen, male and female genitalia and abdominal scent glands. Journal of Animal Morphology \& Physiology. 14[1967]:18-25 + $1 \mathrm{pl}$.

Machida R. 1981. External features of embryonic development of a jumping bristletail, Pedetontus unimaculatus Machida (Insecta, Thysanura, Machilidae). Journal of Morphology. 168:339355.

Manton S. 1972. The evolution of arthropodan locomotory mechanisms. Part 10. Locomotory habits, morphology and evolution of the hexapod classes. Journal of the linnean Society of London, Zoology. 51:203-400.

Mashimo Y, Machida R. 2017. Embryological evidence substantiates the subcoxal theory on the origin of pleuron in insects. Scientific Reports. 7:12597. doi: 10.1038/s41598-017-12728-2

Matsuda R. 1957. Comparative morphology of the abdomen of a machilid and a rhaphidiid. Transactions of the American entomological Society. 83:39-63+5 pl.

Matsuda R. 1970. Morphology and evolution of the insect thorax. Memoirs of the entomological Society of Canada. no76:1-431.

Matsuda R. 1976. Morphology and evolution of the insect abdomen. Oxford: Pergamon Press. viii + $523 \mathrm{pp}$.

Matushkina NA. 2008. Skeletomuscular development of genital segments in the dragonfly Anax imperator (Odonata, Aeshnidae) during metamorphosis and its implications for the evolutionary morphology of the insect ovipositor. Arthropod Structure \& Development. 37:321-332.

Metcalfe ME. 1932a. The structure and development of the reproductive organs in the Coleoptera with notes on its homologies. Quarterly Journal of microscopical Science. 75:49-129.

Metcalfe ME. 1932b. Notes on the structure and development of the reproductive organs in Philaenus spumarius. Quarterly Journal of microscopical Science. 75:49-129.

Mickoleit G. 1973. Ueber Ovipositor der Neuropteroidea und Coleoptera und seine phylogenetische Bedeutung. Zeitschrift für Morphologie der Tiere. 74:467-481.

Mickoleit G. 1975. Die Genital- und Postgenital Segmente der Mecoptera-Weibchen. I. Das Exoskelet. Zeitschrift für Morphologie der Tiere. 80:97-135.

Mickoleit G. 1976. Die Genital- und Postgenitalsegmente der Mecoptera-Weibchen (Insecta, Holometabola). II. Das Dach der Genitalkammer. Zoomorphologie. 85:133-156.

Milne-Edwards H. 1851. Introduction à la zoologie générale, ou, considérations sur les tendances de la nature dans la constitution du règne animal. $1^{\mathrm{e}}$ partie. Paris: Masson, $180 \mathrm{pp}$.

Naomi S-I. 2014. The lateral sclerites of the pregenital abdominal segments in Coleoptera (Arthropoda: Hexapoda). Japanese Journal of systematic Entomology. 20:319-335. 
Nielsen ES. 1980. A comparative study of the genital segments and the genital chamber in female Trichoptera. Biologiske Skrifter, Det Kongelige Danske Videnskabernes Selskskab. 23:1200.

Niwa N, Akimoto-Kato A, Niimi T, Tojo K, Machida R, Hayashi S. 2010. Evolutionary origin of the insect wing via integration of two developmental modules. Evolution \& Development. 12:168-176.

Prell H. 1913. Das Chitinskelett von Eosentomon. Zoologica. Original-Abhandlungen aus dem Gesammgebiete der Zoologie. 25 (64):58 pp., 6 pls.

Prokop J, Pecharová M, Nel A, Hörnschemeyer T, Krzemińska E, Krzemiński W, Engel MS. 2016. Paleozoic nymphal wing pads support dual model of insect wing origins. Current Biology. [2016]: http://dx.doi.org/10.1016/j.cub.2016.11.021. [2017]: 27:1-7.

Qadri MAH. 1940. On the development of the genitalia and their ducts of orthopteroid insects. The Transactions of the Royal entomological Society, London. 90:121-175, + pls 1-7.

Rasnitsyn AP. 1981. A modified paranotal theory of insect wing origin. Journal of Morphology. 168:331-338.

Rees BE, Ferris GF. 1939. The morphology of Tipula reesi Alexander (Diptera: Tipulidae). Microentomology 4:143-178.

Ritcher PO. 1969. Spiracles of adult Scarabaeoidea (Coleoptera) and their phylogenetical significance. 1. The abdominal spiracles. Annals of the entomological Society of America. 62:869-880.

Rousset A. 1973. Squelette et musculature des régions génitales et postgénitales de la femelle de Thermobia domestica (Packard). Comparaison avec la région génitale de Nicoletia sp. (Insecta: Apterygota: Lepismatida). International Journal of Morphology \& Embryology. 2:55-80.

Scudder GGE. 1957. Reinterpretation of some basal structures in the insect ovipositor. Nature. 180:340-341.

Scudder GGE. 1961a. The comparative morphology of the insect ovipositor. Transactions of the Royal entomological Society of London. 113:25-40.

Scudder GGE. 1961b. The functional morphology and interpretation of the insect ovipositor. The Canadian entomologist. 93:267-272.

Scudder GGE. 1964. Further problems in the interpretation and homology of the insect ovipositor. The Canadian Entomologist. 96:405-417.

Scudder GGE. 1971. Comparative morphology of insect genitalia. Annual Review of Entomology. 16:379-406.

Sharov AG. 1966. Basic arthropodan stock. New York: Pergamon Press, 271 pp.

Singh-Pruthi H. 1924. On the post-embryonic development and homologies of the male genital organs of Tenebrio molitor (Coleoptera) with remarks on the comparison of the latter organs in the two sexes. Proceedings of the zoological Society of London. 46:869-883, $+1 \mathrm{pl}$.

Smith EL. 1969. Evolutionary morphology of external insect genitalia. 1. Origin and relationships to other appendages. Annals of the entomological Society of America. 62:1051-1079.

Snodgrass RE. 1927. Morphology and mechanism of the insect thorax. Smithsonian miscellaneous Collections. 80:1-108.

Snodgrass RE. 1931. Morphology of the insect abdomen. Part I. General structure of the abdomen and its appendages. Smithsonian miscellaneous Collections. 85:1-128.

Snodgrass RE. 1933. Morphology of the insect abdomen, Part II. The genital ducts and the ovipositor. Smithsonian miscellaneous Collections. 89:1-148.

Snodgrass RE. 1935a. Principles of insect morphology. New York, London: McGraw Hill, ix +667 $\mathrm{pp}$.

Snodgrass RE. 1935b. The abdominal mechanisms of a grasshopper. Smithsonian miscellaneous Collections. 94, no 6:1-89.

Snodgrass RE. 1952. A textbook of arthropod anatomy. Ithaca, New York: Comstock Publ. Assoc., Cornell University Press, $x+363$ pp. 
Snodgrass RE. 1958. Evolution of arthropod mechanisms. Smithsonian miscellaneous Collections. 138:1-77.

Snodgrass RE. 1963. A contribution toward an encyclopedia of insect anatomy. Smithsonian miscellaneous Collections. 146:1-48.

Styš P. 1959. Reinterpretation of the theory on the origin of the pterygote ovipositor and notes on the terminology of the female ectodermal genitalia of insects. Acta Universitatis Carolinae Biologica. 1:75-85.

Sweet MH. 1981. The external morphology of the pre-genital abdomen and its evolutionary significance in the order Hemiptera (Insecta). Rostria. 33 (Suppl.):41-51.

Sweet MH. 1996. Comparative external morphology of the pregenital abdomen of the Hemiptera, pp. 119-158. In: Schaefer CW, editor. Studies on hemipteran phylogeny. Entomological Society of America: Thomas Say Publications in Entomology.

Tanner VM. 1927. A preliminary study of the genitalia of female Coleoptera. Transactions of the American entomological Society. 53:5-50.

Uchifune T, Machida R. 2005. Embryonic development of Galloisiana yuasai Asahina, with special reference to external morphology (Insecta: Grylloblattodea). Journal of Morphology. 266:182-207.

Ungerer P, Wolff C. 2005. External morphology of limb development in the amphipod Orchestia cavimana (Crustacea, Malacostraca, Peracarida). Zoomorphology. 124:89-99.

Vandel A. 1949. Embranchement des Arthropodes (Arthropoda, Siebold et Stannius 1845). Généralités. Composition de l'Embranchement. pp. 79-158. In: Grassé P-P., editor. Traité de Zoologie. Tome 6. Paris: Masson Publ., 980 pp.

Verhoeff C. 1918. Zur vergleichenden Morphologie des Abdomens der Coleopteren und über die phylogenetische Bedeutung desselben, zugleich ein zusammenfassender kritischer Rückblick und neuer Beitrag. Zeitschrift für wissentschaftliche Zoologie. 117:130-204.

Weber H. 1928. Die Gliederung der Sternopleuralregion des Lepidopterenthorax. Eine vergleichende morphologische Studie zur Subcoxaltheorie. Zeitschrift für wissenschaftliche Zoologie. 131:181-254.

Weber H. 1933. Lehrbuch der Entomologie. Jena:1-726.

Weber H. 1952. Morphologie, Histologie und Entwicklungsgeschichte der Articulaten. Fortschritte der Zoologie. NF. 9: 1-231.

Weber H. 1966. Grundriss der Insektenkunde. Stuttgart: Gustav Fischer Verlag, 1-428.

Wesener T, Sierwald P, Wägele J-W. 2014. Sternites and spiracles - The unclear homology of ventral sclerites in the basal millipede order Glomeridesmida (Myriapoda, Diplopoda). Arthropod Structure \& Development. 43:87-95.

Wigglesworth VB. 1973. Evolution of insect wings and flight. Nature. 246 (5429):127-129.

Willem V. 1900. Recherches sur les Collemboles et les Thysanoures. Mémoires couronnés et mémoires des savants étrangers, publiés par l'Académie royale des sciences, des lettres et des beaux-arts de Belgique. 58:1-144.

Williams GJA, Shivers RR, Caveney S. 1984. Active muscle migration during insect metamorphosis. Tissue and Cell. 16:411-432.

Wolff C. 2009. The embryonic development of the malacostracan crustacean Porcellio scaber (Isopoda, Oniscidea). Development Genes and Evolution. 219:545-564. 


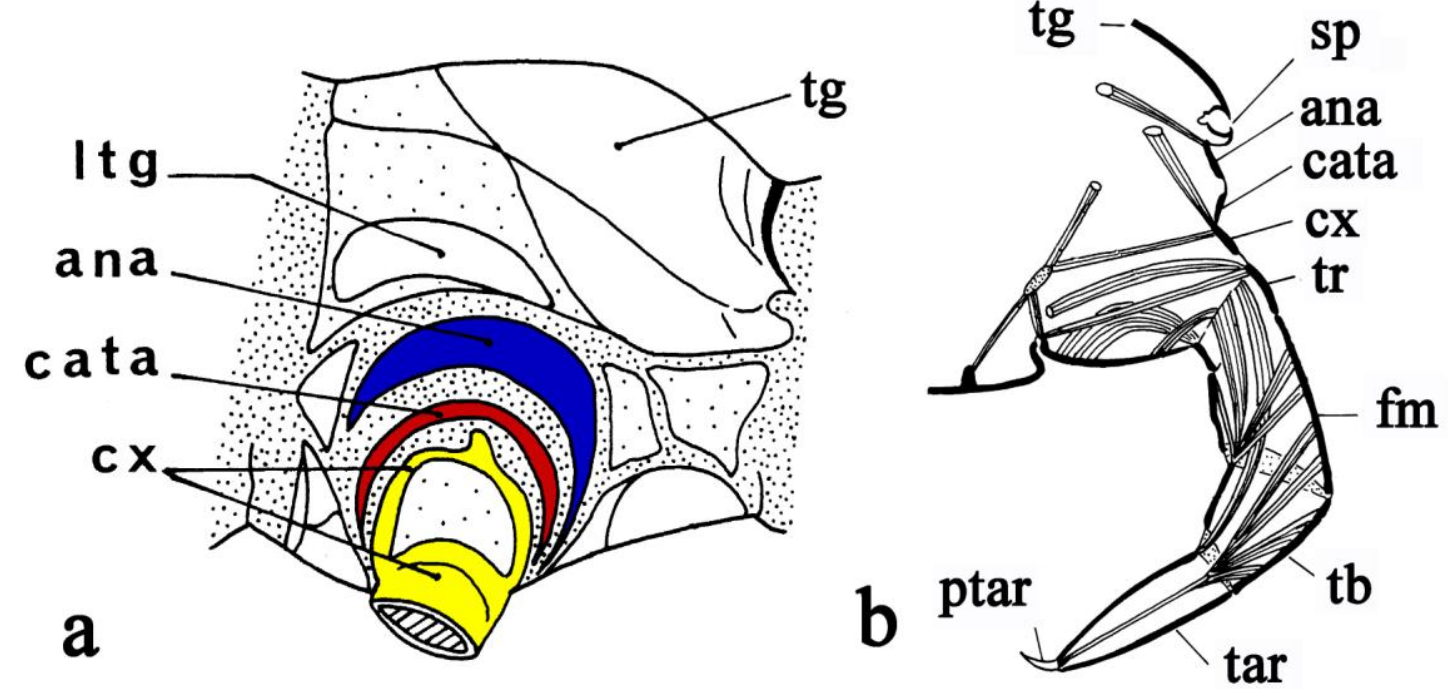

Figure 1. Mesothoracic segment of proturans (after François 1964, modified). a. Lateral view of the external morphology in Acerentomon. There is a so-called laterotergite more dorsal than the anapleurite and located on the lateral margin of the tergum. It might be a tergopleurite. b. Section of the appendage and of more dorsal areas in Eosentomon. Note the position of the spiracle above the anapleurite on the lateral margin of the tergum, in a probably tergopleural area.

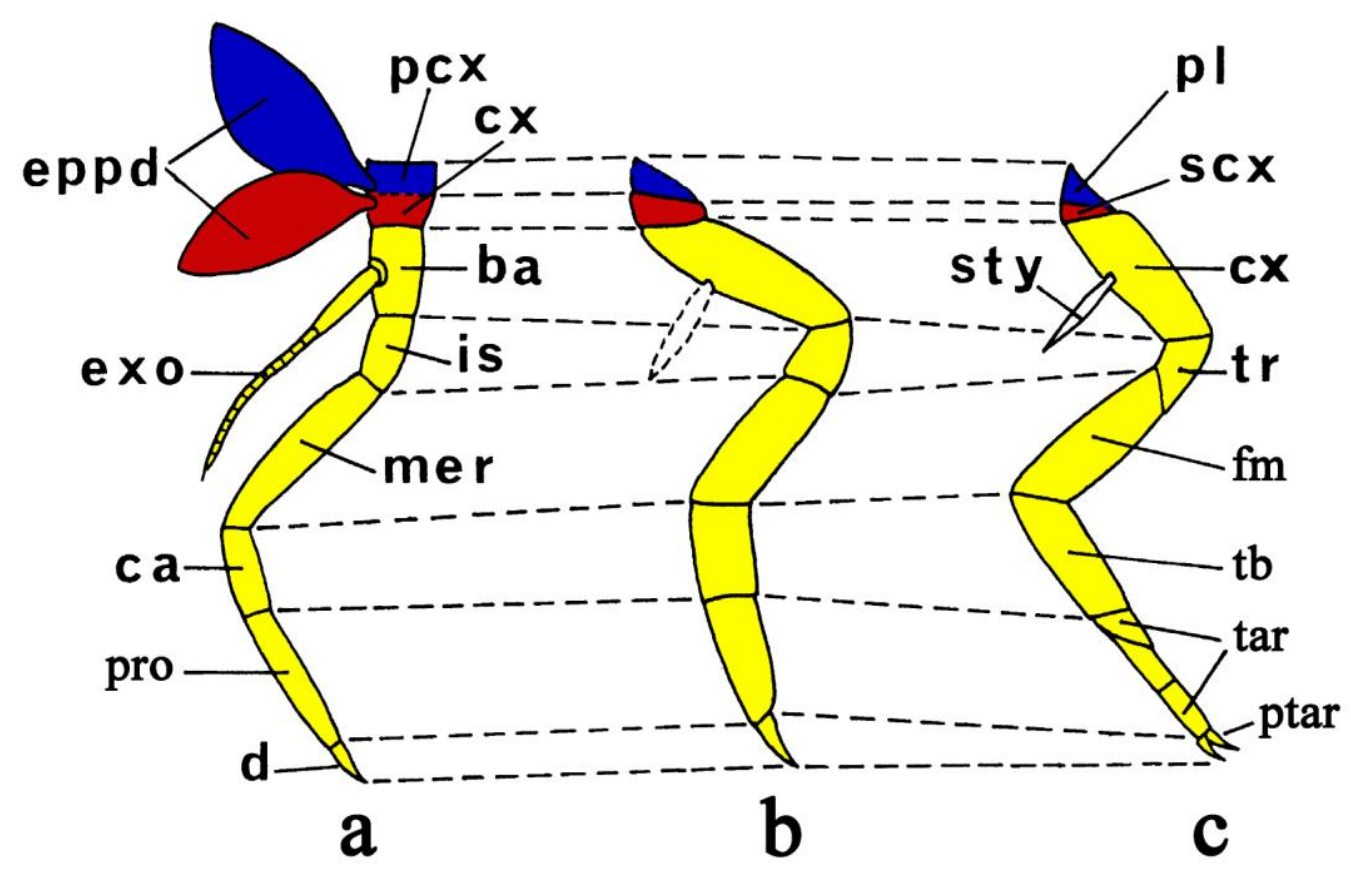

Figure 2. Homologies of the respective segments of the appendage of an Anaspides sp. (Crustacea, Syncarida) (a), a Palaeozoic monuran (b) and a machilid (Archaeognatha) (c) (after Sharov 1966). The precoxa of the machilid was named "pleurite" by Sharov. It is noteworthy that the hexapodan subcoxa corresponds to the coxa of the crustaceans and that the hexapodan coxa corresponds to the basis of the crustaceans. 


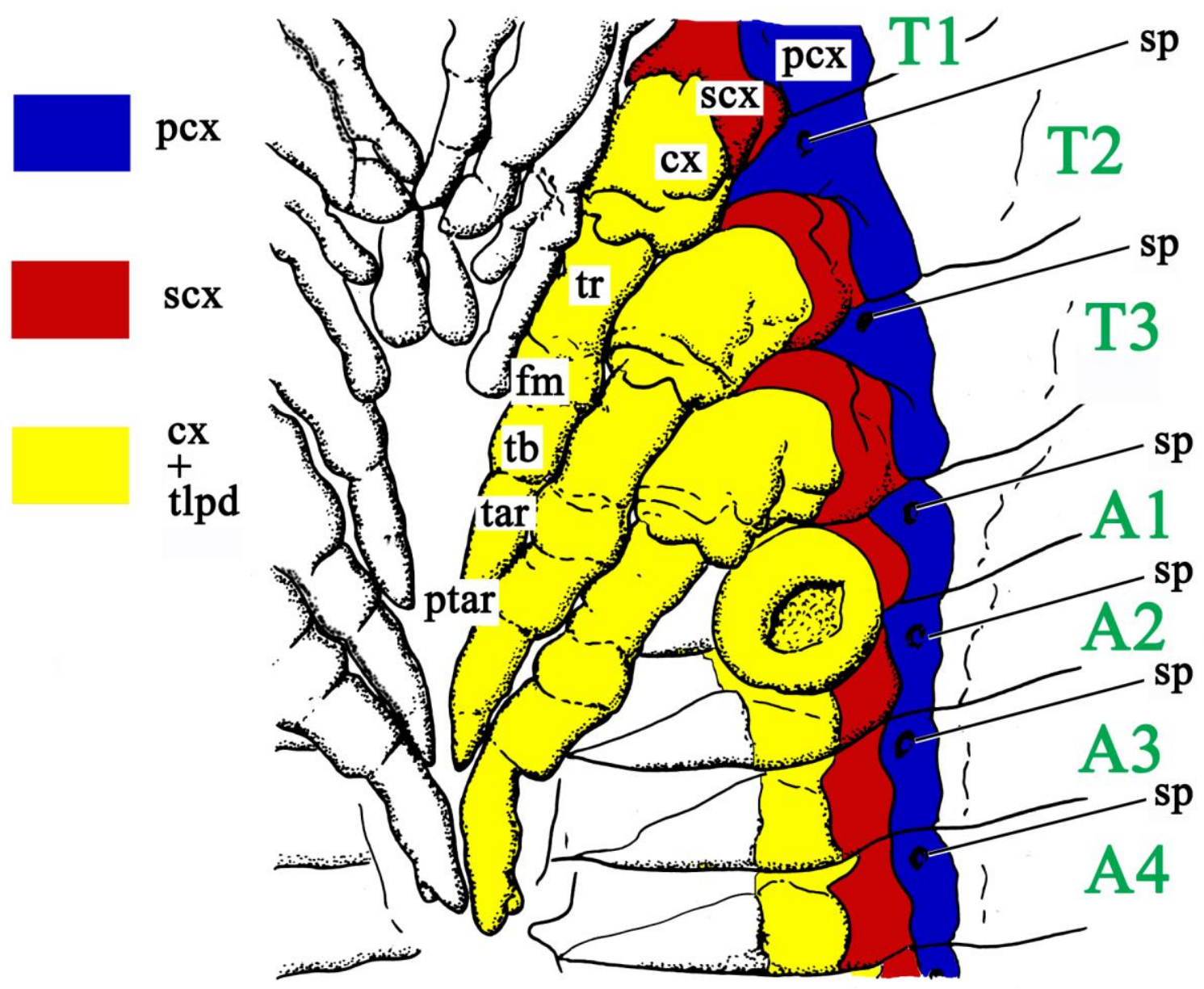

Figure 3. Carabus insulicola (Coleoptera, Carabidae). Embryo fixed at 60\% DT (percentage of total developmental time, from oviposition to hatching), showing thoracic segments and four abdominal segments (after Kobayashi et al. 2013, modified). Different colours refer to the apparent longitudinal fields, blue: precoxal - red: subcoxal - yellow: coxal and telopodal. The discoid organ lying in the coxal area of the first abdominal segment is the pleuropodium. 

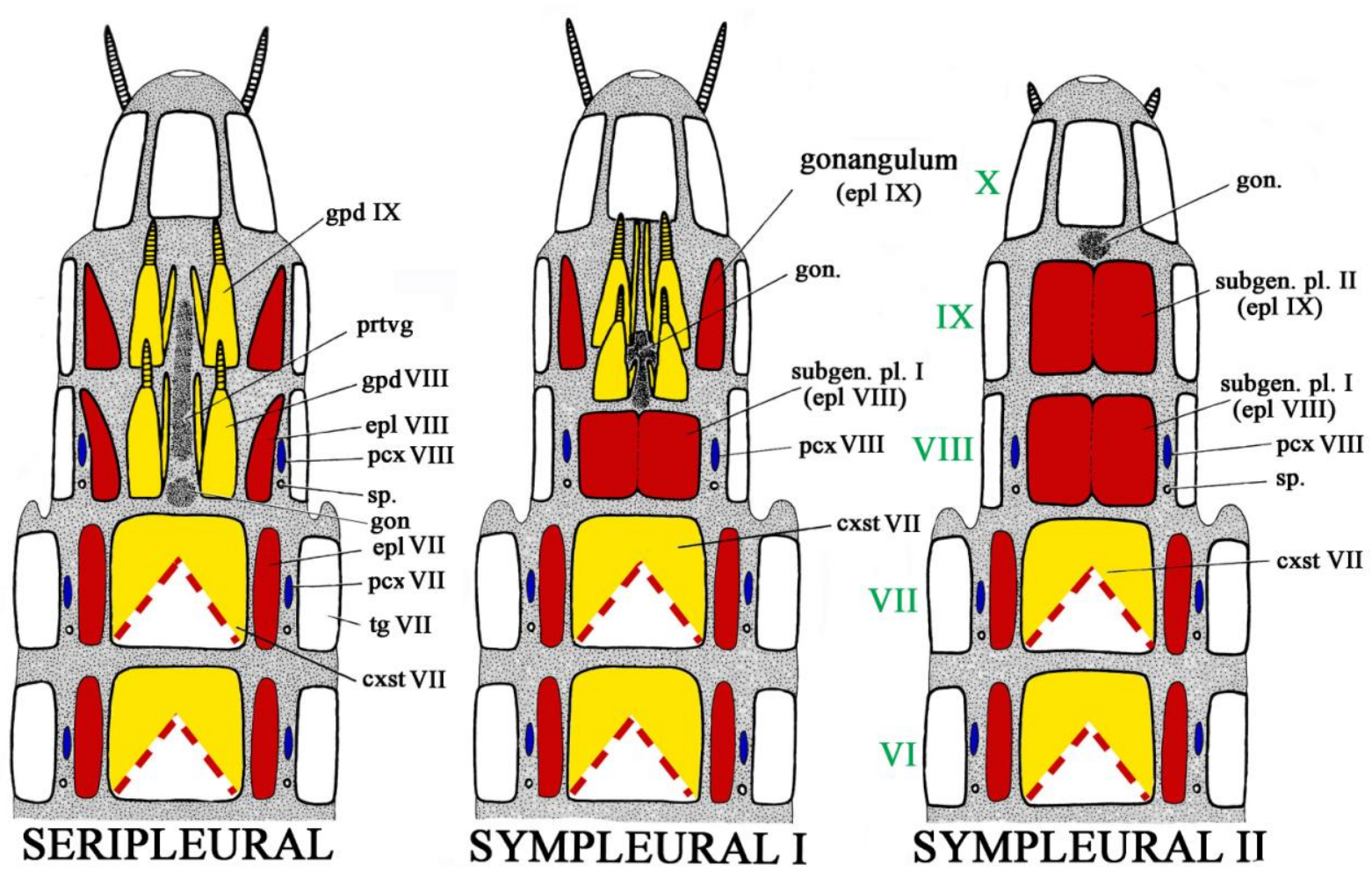

Figure 4. Diagrams of the three theoretical abdominal types in female ectognathan hexapods: seripleural, sympleural-I and sympleural-II types. Note that the borders of the coloured regions for the coxosternal plates are arbitrary, being intended only to indicate existence of coxal, subcoxal and sternal components; for simplicity, no precoxal component are represented. In the seripleural type, the original metameric arrangement is maintained; the primary gonopore lies behind segment VII. In sympleural-I type, gonopods VIII join gonopods IX to form an ovipositor; epipleurites IX correspond to gonangula with an articular function; epipleurites VIII join ventrally to form the first subgenital plate that closes the abdomen; the secondary gonopore is apparently located at the rear of segment VIII. In the sympleural-II type, the gonopods are regressed; epipleurites IX join ventrally to form a second subgenital plate; the secondary gonopore is apparently located at the rear of segment IX.

Colours refer to the different limb segments, blue: precoxal - red: subcoxal - yellow: coxal and telopodal. 

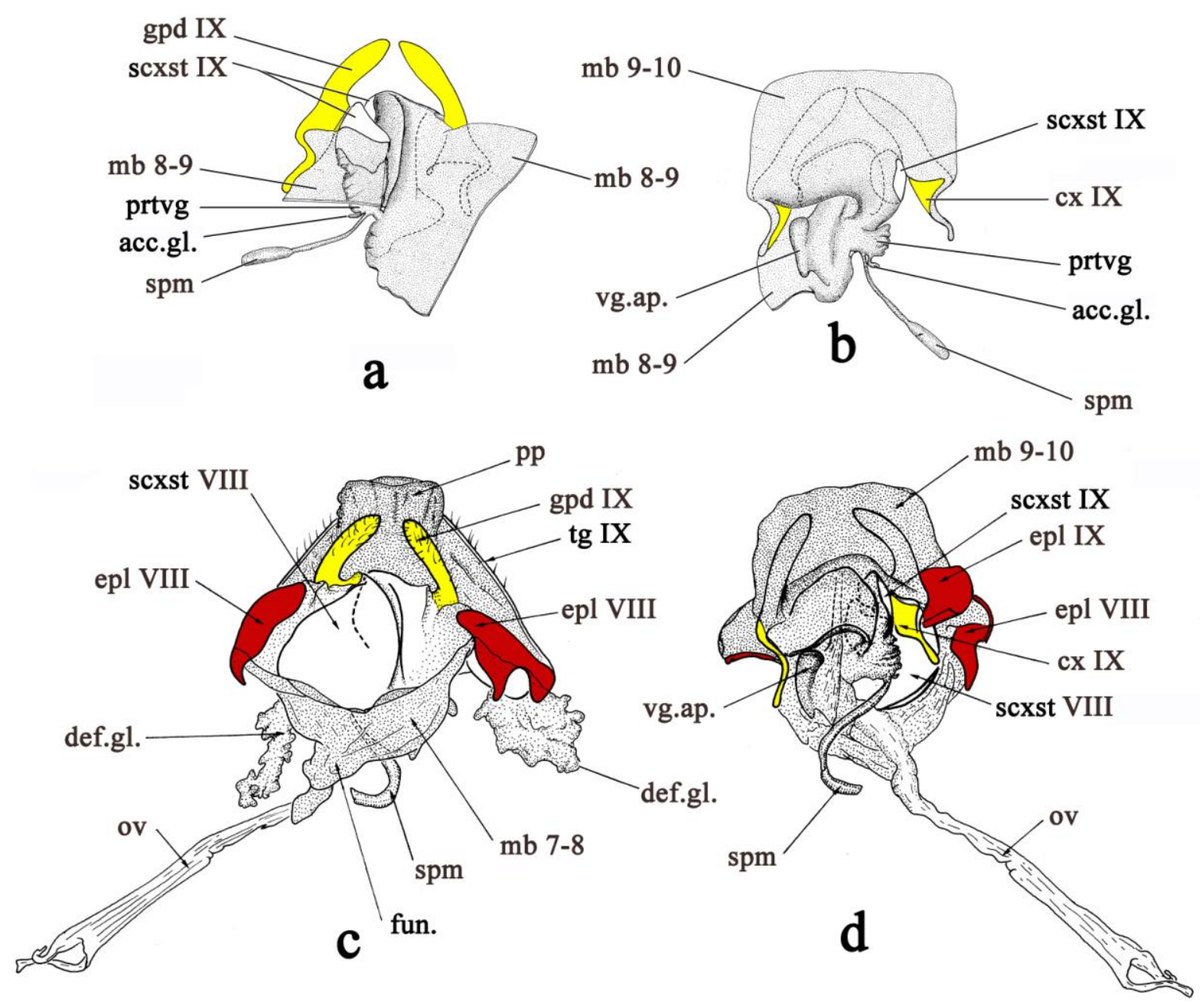

Figure 5. Female ectodermal genitalia of Eustra leclerci (Coleoptera, Paussidae), external views (a, c) and internal views $(b, d)$ of the ventral side. a and b. Segment IX: gonopods and subcoxosternal plate. The protovagina is shaped, with formation of the spermatheca, accessory gland and vaginal apophysis, but the whole is still separated from the oviductal pouch. c and d. Segments VIII and IX. There is a large subcoxosternal plate VIII between the epipleurites VIII. The oviductal pouch is located anterior to this plate, in the form of a membranous funnel into which the common oviduct opens. 


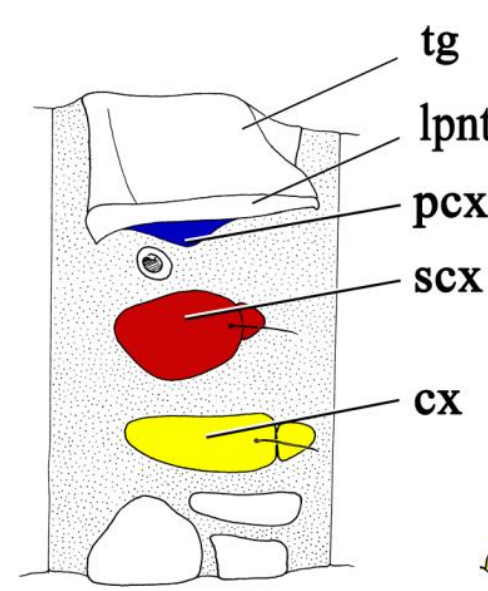

a

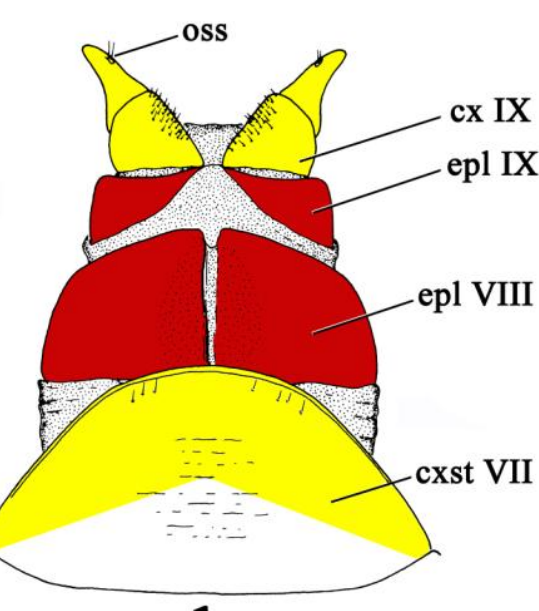

b

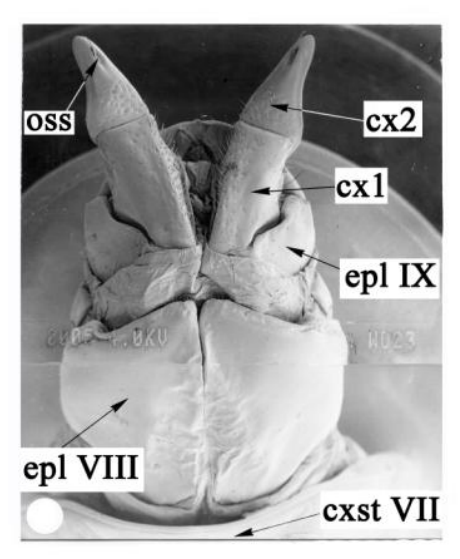

C

Figure 6. Carabus sp. (Coleoptera, Carabidae). a. Abdominal segment of a larva, lateral view. Note the presence of a precoxal territory on the ventral flank of the paranotal lobe, near the spiracle. b. Distal extremity of the female abdomen. Note the distinctly bipartite morphology of the ventrite VIII, formed by juxtaposition of the two epipleurites. Gonopod IX is dimeric. c. Idem, scanning electron micrograph.

Different colours indicate the longitudinal fields, blue: precoxal - red: subcoxal - yellow: coxal and telopodial. Note that the borders of the coloured regions for the coxosternal plates are arbitrary, being intended only to indicate existence of coxal, subcoxal and sternal components; for simplicity, no precoxal component are represented. 


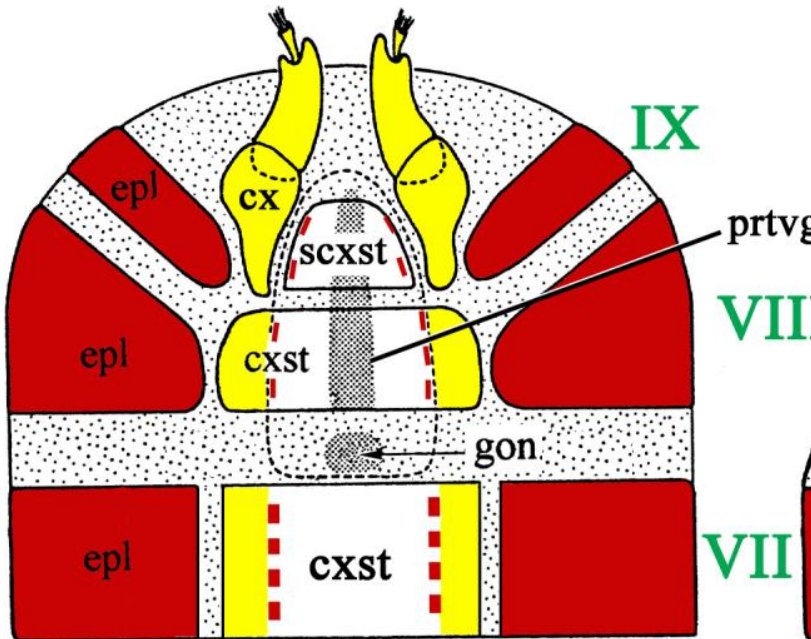

a

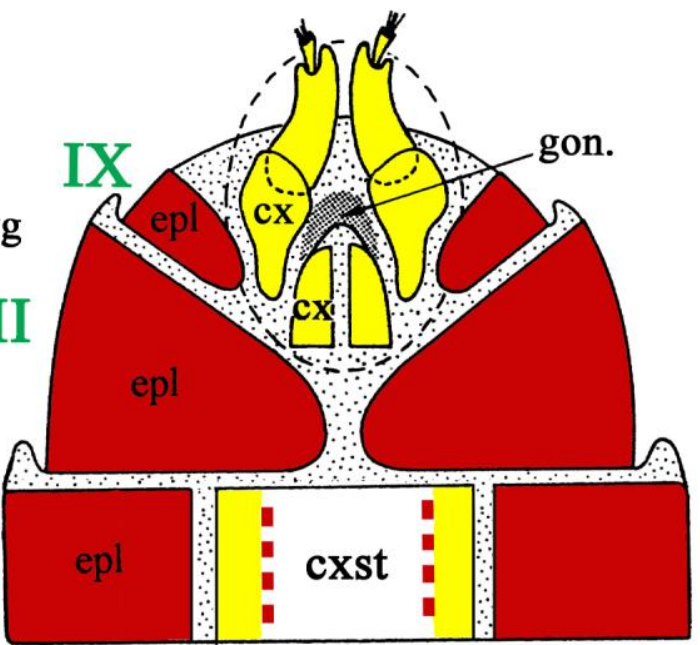

b

\section{epitopic (sympleural I)}

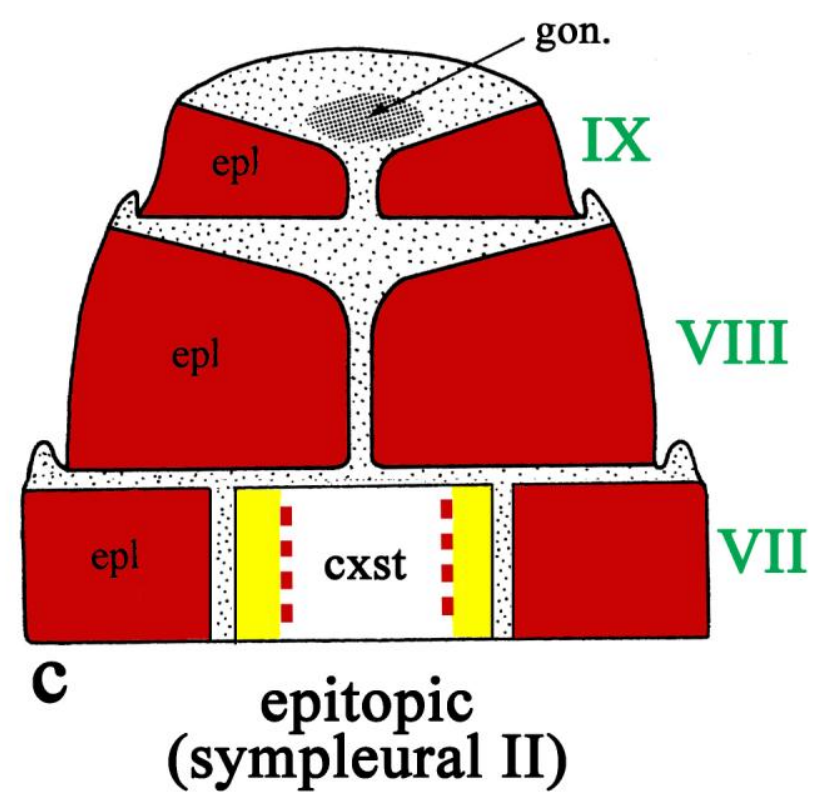

Figure 7. Diagrams illustrating the rearward displacement of the gonopore in a female insect. Note that the colours of the coxosternal plates are here arbitrary, intended only to remind the existence of coxal, subcoxal and sternal components; for simplicity, no precoxal component is represented. In the orthotopic stage (a. seripleural type), the metameric organisation is maintained and the gonopore is located at the rear of segment VII. Note the separation of the primary gonopore (oviductal pouch) and the protovagina. The dashed line indicates the area that will be internalised to form the epitopic gonopore, located at the rear of segment VIII (b. sympleural-I type) or at the rear of segment IX (c. sympleural-II type). Note the anatomical and functional dissociation of the epipleurites and the coxosternal plates. 


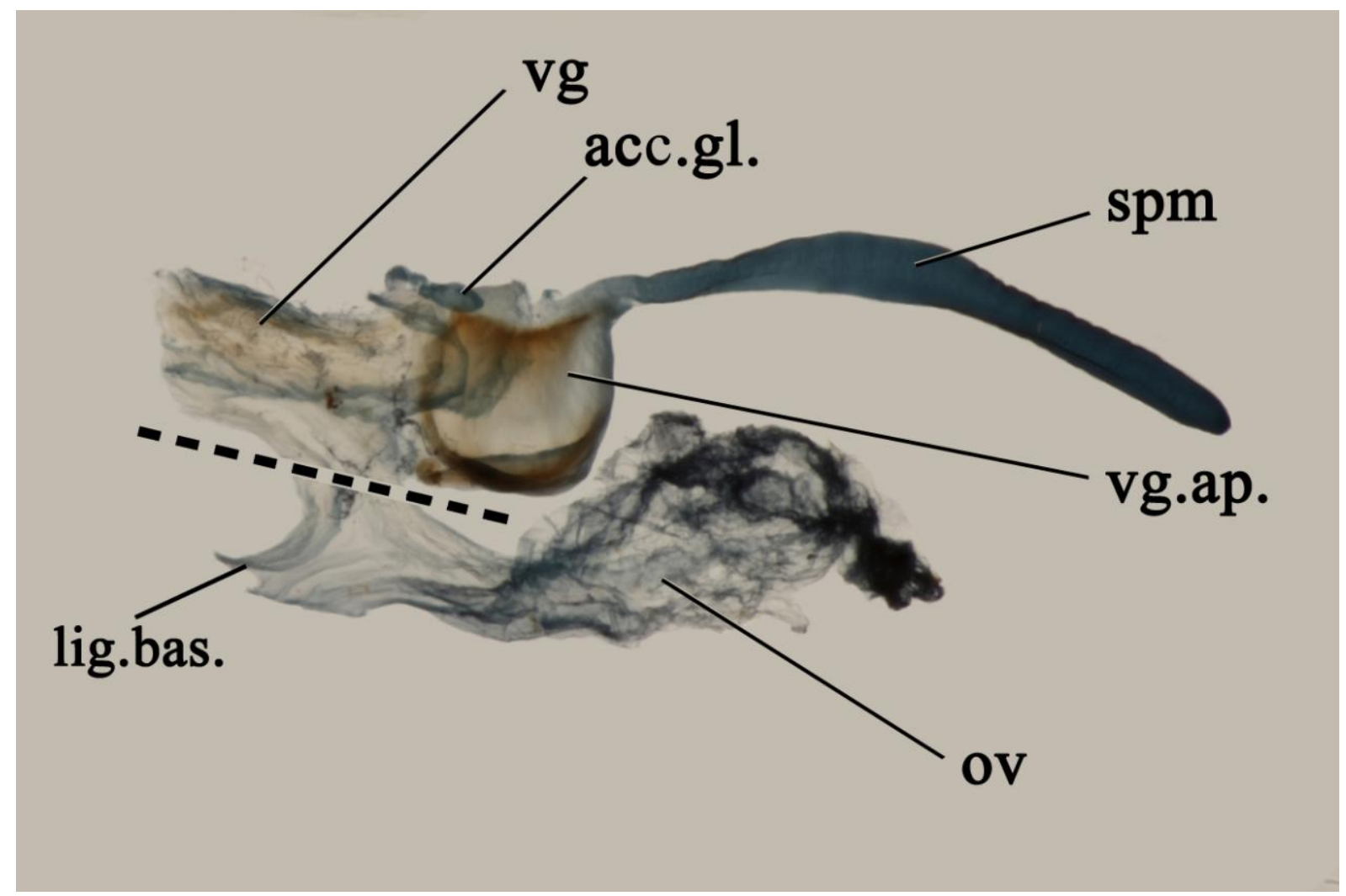

Figure 8. Female ectodermal genitalia of Pachyteles granulatus (Coleoptera, Paussidae). The dashed line separates the oviductal components (segment VII) from the vaginal components (segments VIII and IX). 


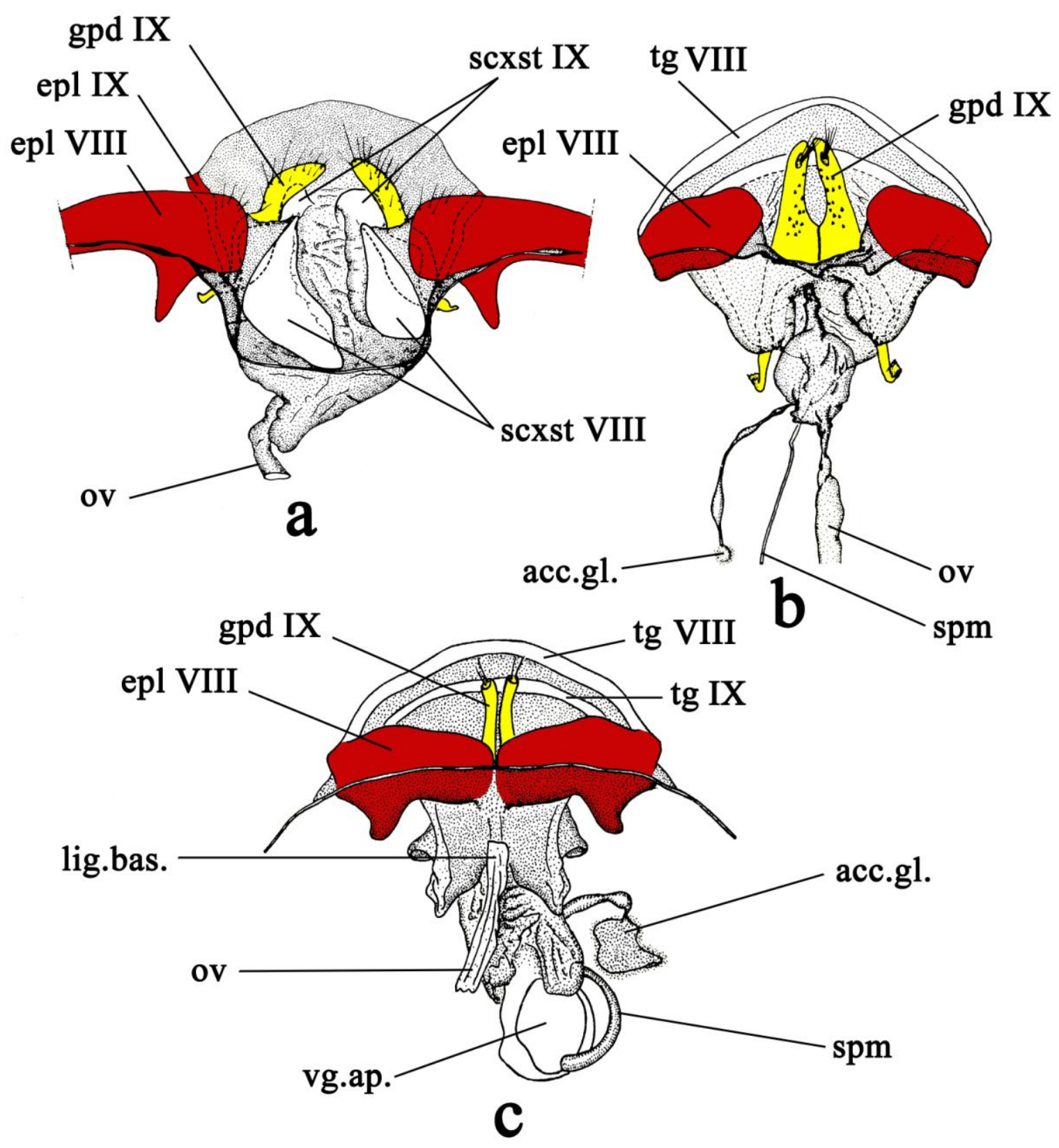

Figure 9. Illustration of the abdominal closure by juxtaposition of the epipleurites VIII in various female Paussidae (Coleoptera). a. Eustra lebretoni, in which the epipleurites VIII are in lateral position, still separated from each other by the presence of the subcoxosternal plate VIII. Some elements of subcoxosternum IX are still visible between the gonopods. The oviductal pouch is separated from the protovaginal formations. b. Sphaerostylus punctatostriatus, in which epipleurites VIII are still in lateral position, but the subcoxosternal areas VIII and IX are internalised and the oviduct opens into the vaginal duct. c. Tachypeles pascoei, in which epipleurites VIII and IX joined and are juxtaposed to form a new ventral plate or 'tertiary sternum'. A ligula basalis can be observed, perhaps representing a vestige of the primary gonopore. 

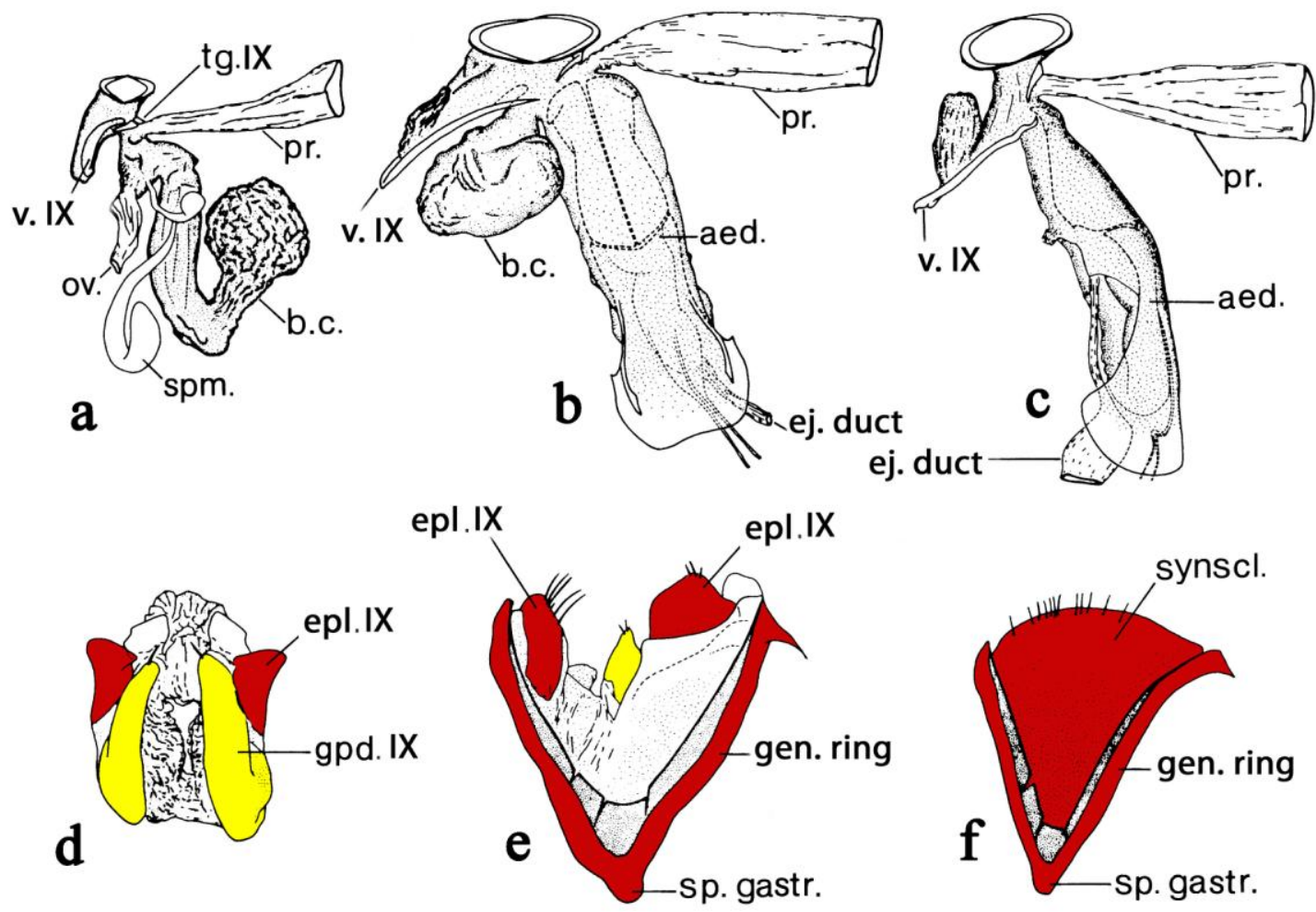

Figure 10. Internal (Figures a-c) and external (Figures d-f) genitalia in Cotinis mutabilis (Coleoptera, Cetoniidae) (after Deuve 1992): a and d, female; b and e, gynandromorph; c and f male. a. In the female, the exodermal genital ducts are well shaped, with oviduct, bursa copulatrix, spermatheca and spermathecal gland. b. In the gynandromorph, the female components are vestigial, with poorly shaped bursa copulatrix but without oviduct or spermatheca; the male components are fully formed, with a complete aedeagus, but its rotation is incomplete $\left(90^{\circ}\right.$ instead of $\left.180^{\circ}\right)$. c. In the male, the aedeagus is complete, with $180^{\circ}$ rotation. d. In female, the external genitalia show lateral epipleurites IX (subcoxae) and developed gonopods VIII (coxae). e. In the gynandromorph, the ventrite IX is decomposed into distinct epipleural and coxal elements, but the VIII-IX costal area shows a 'genital ring' and a normally shaped spiculum gastrale. f. In the male, the ventrite IX (synsclerite) would be formed from totally merged epipleurites IX. 

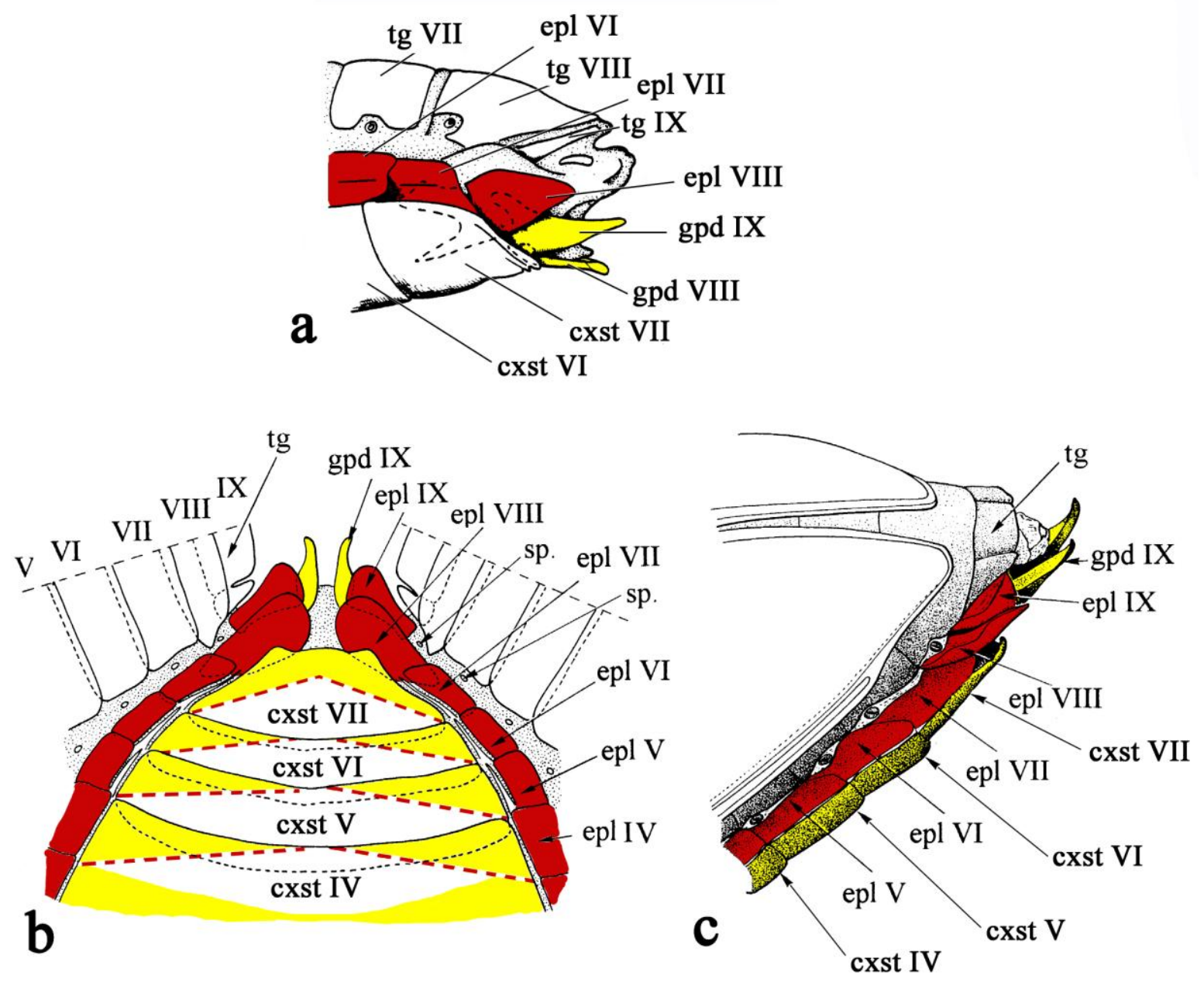

Figure 11. Distal extremity of the abdomen in beetles, illustrating the dissociation of epipleurites and coxosternites. a. Stictotarsus duodecimpustulatus (Dytiscidae), lateral view (after Burmeister 1976, modified). It is noteworthy that epipleurite VIII acquires mobility following its involvement in the ventral closure of segment VIII which follows the internalisation of coxosterna VIII and IX. b. Systolosoma breve (Trachypachidae). Ventral and dorsal views, the tergites having been cut along the midline. The alignment of the epipleurites is clearly visible. Subcoxosternal plates VIII and IX are entirely internalised. Note that the borders of the coloured regions for the coxosternal plates are arbitrary, being intended only to indicate existence of coxal, subcoxal and sternal components; for simplicity, no precoxal components are represented. c. Systolosoma breve, lateral view. 